\title{
Source-Sink Modifications Affect Leaf Senescence and Grain Mass in Wheat
}

Xuemei Lv ${ }^{1,2}$, Yan Zhang ${ }^{1,2}$, Yunxiu Zhang ${ }^{2}$, Shoujin Fan ${ }^{1}$ and Lingan Kong ${ }^{1,2, * 1}$ College of Life Science, Shandong Normal University, Jinan 250014, China

${ }^{2}$ Crop Research Institute, Shandong Academy of Agricultural Sciences, Jinan 250100, China

Running title: Source-sink modifications in wheat

* Corresponding author:

Lingan Kong, Ph.D.

College of Life Science

Shandong Normal University

88 Wenhuadong Road

Jinan City 250014

China

Tel.: $\quad$ 0086-531-66658123

Fax: $\quad$ 0086-531-66659088

E-mail address: kongling-an@ 163.com 


\section{Abstract}

2 A field experiment was performed in wheat to investigate the responses of flag leaf and grain to

3 sink/source manipulations. The results showed that half-degraining delayed but defoliation (only

4 flag leaf left) enhanced the leaf senescence. Sink/source manipulations influenced the content of

5 reactive oxygen species of flag leaf and the content of phytohormones including cytokinins,

6 indoleacetic 3-acid, gibberellin 3, salicylic acid and jasmonic acid in the defoliated flag leaf (DL)

7 and grain (DG), half-degrained flag leaf (HL) and grain (HG). An iTRAQ based quantitative

8 proteomic analysis indicated that at 16 days after manipulation a total of 97 and 59 differentially

9 expressed proteins (DEPs) from various functional categories were observed in HL and DL groups,

respectively, compared with control and 115 and 121 DEPs were observed in HG and DG groups,

11 respectively. GO annotation terms of DEPs mainly included carbon fixation, hydrogen peroxide

catabolic process, chloroplast and cytoplasm, oxidoreductase activity and glutamate synthase activity in flag leaf of manipulated plants; organonitrogen compound metabolic process, cytoplasm, vacuolar membrane, CoA carboxylase activity, starch synthase activity and nutrient reservoir activity in grain of manipulated plants. KEGG pathway enrichment analysis revealed that photosynthesis, carbon, nitrogen and pyruvate metabolisms and glycolysis/gluconeogenesis

17 were the most remarkable processes for sink/source manipulations. Sink/source manipulations

Keywords: Defoliation, half-degraining, iTRAQ, photosynthesis, leaf senescence, wheat. 


\section{Introduction}

2 The grain yield of cereals is determined by the synergistic reaction between source activity and

3 sink capacity. Source supply reserves accumulated there to sink (the developing grains). Sink

4 strength is determined by the number and potential size of grains per stem, depending on the

5 capacity to actively obtain from photosynthetic assimilates and reserves in the vegetative organs

6 and accumulate these compounds.

7 Wheat (Triticum aestivum L.) productivity is generally considered to be a sink-limited under

8 favorable conditions with grain development regulated by the assimilating capacity during grain

9 filling, is hardly limited by the source (Foulkes et al., 2011), because that the wheat source

generally has the capacity to provide adequate assimilates to the developing grains. However, the

11 inconsistent conclusions have also observed. An increase in the source/sink ratio do not affect the

grain mass (Calderini and Reynolds 2000; Calderini et al., 2006). Defoliation in old germplasm of

bread wheat does not cause source limitation to grain filling (Kruk et al., 1997). The grain yields

are co-limited both by the source and the sink in wheat (Kruk et al., 1997; Beed et al., 2007).

Experiments with manipulation of assimilate availability during grain filling found that the wheat

yields are mainly limited by the sink size (Borŕas et al., 2004). Slafer and Savin (1994) reported

that the grain yield of wheat is either sink-limited or co-limited by both source and sink but never

source-limited. Therefore, better understanding of source-sink interaction would help propose strategies to improve yield potential using genetic avenues. 
1 gibberellin (GA) show a contrasting response (Yang et al., 2000; Chang and Zhu, 2017; Jan et al.,

2 2019). In addition, various studies have outlined the cross-talk among various hormones. They can

3 be directly involved in the regulation of senescence or function antagonistically. In addition,

4 interactions of phytohormones with other factors, such as nitrogen status and sugar signaling, play

5 a critical role in regulating source and sink communication between (Paul and Foyer, 2001;

6 Thomas and Ougham, 2014). Therefore, the regulation of senescence by hormones is a

7 complicated process that needs deeper investigation.

8 As a powerful technique to perform quantitative proteome analysis, isobaric tag for relative

9 and absolute quantitation (iTRAQ) allows identification of more numerous proteins and can

10 provide more reliable quantitative information than traditional 2-DE analysis (Karp et al., 2010).

11 With a sufficient number of proteins it is possible to construct pathways and perform

protein-protein interaction (PPI) analyses (Wang and You, 2012). The proteomics studies in wheat

using iTRAQ were primarily on performed for investigating the protein responses to stress such as

drought, reactive oxygen species (ROS) stress and nutrient deficiency to assess the effects of and You, 2012). To date, however, quantitative proteomics studies based on iTRAQ analysis on been reported. 
1 1994; Ma et al., 1996) and barley (Cartelle et al., 2006). Unfortunately, although much effort has

2 been made, we are still far from fully understanding source-sink interaction and even further from

3 rational manipulation of the source-sink relationship (Chang and Zhu, 2017). How it can be

4 regulated by cultivation means and genetic manipulations remained unclear.

5 The study reported here was designed to examine the impact of manipulating the source/sink

6 ratio on the physiological modifications and protein expression in flag leaf and grain, aiming to

7 determine how the leaf senescence and grain yield is regulated by changing the availability of

8 potential assimilates for per grain. These results might promote better understanding of the roles of

9 source-sink relationship in grain development and finding effective avenues, such as genetic

10 modifications in breeding, to further increase cereal grain yield.

\section{Results}

\section{NDVI, PRI and SPAD values}

13 The changes in NDVI, PRI and SPAD values of the flag leaves exhibited similar trends (Table 1).

14 Three parameters were gradually decreased with the progress of grain filling. The PRI values

15 showed the greater sensitivity to sink-source modifications than SPAD and NDVI. Significant

differences in PRI values were observed between three treatments and between growth stages.

17 However, the differences in NDVI values were only observed between half-degraining and

\section{Chlorophyll fluorescence}


1 The value of flag leaf $F v / F m$ remained unaffected during experiment period for half-degraining

2 treatment compared with the intact control, while the value was significantly lower for defoliation

3 than control (Fig. 1). The difference in $\Phi_{\text {PSII }}$ value between half-degraining and control was only

4 observed at 16 DAM, while the $\Phi_{\mathrm{PSII}}$ value were significantly lower for defoliation than degrained

5 and control plants (Fig. 1).

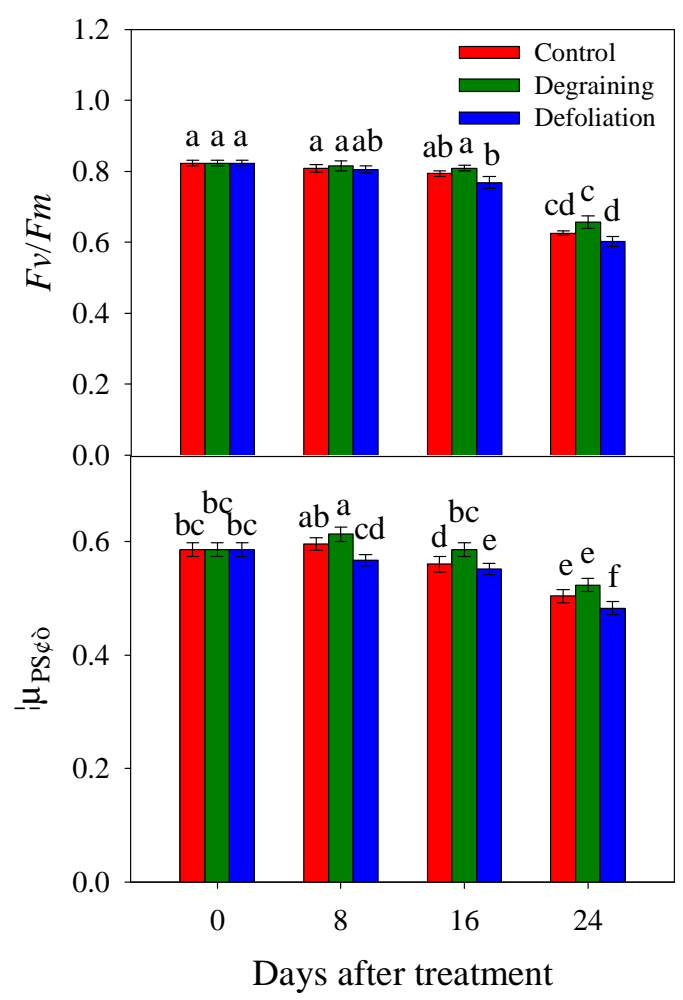

7 Fig. 1. Effects of sink/source manipulation on fluorescence parameters of flag leaves in wheat. (A)

$8 F v / F m$ : maximal efficiency of PSII photochemistry; $\Phi_{\text {PSII }}$ actual PSII efficiency. Each value is the

9 mean \pm standard deviation (SD) from at least six leaves. The columns labeled with different letters differed significantly at $p<0.05$ according to Duncan's multiple range test.

\section{Chloroplast Structure}

At 16 DAM, visual observation did not find difference in senescing flag leaf between three 
1 treatments, however, the obvious difference in cell ultrastructure of leaf tissues was observed under transmission electron microscopy (Fig. 2). The chloroplasts were spherical in all three treatments. In cells of degrained flag leaf (Fig. 2A), the chloroplasts contained a larger number of thylakoids and the matrix of the chloroplasts was still dense in comparison to the control (Fig. 2B) and defoliation treatment (Fig. 2C). In cells of defoliated flag leaf, numerous small vesicles or membrane-like fragments were observed in the cytoplasm (Fig. 2C). The membranes constituting the thylakoids were more distinct and abundant in cells of degrained flag leaf. But in control and defoliation treatments, the structure of the thylakoids was characterized by loss of the parallel arrangement of the grana lamellae in some chloroplasts, and some of the thylakoids became swollen. In cells of flag leaf with defoliation treatment, the number of chloroplasts decreased noticeably.

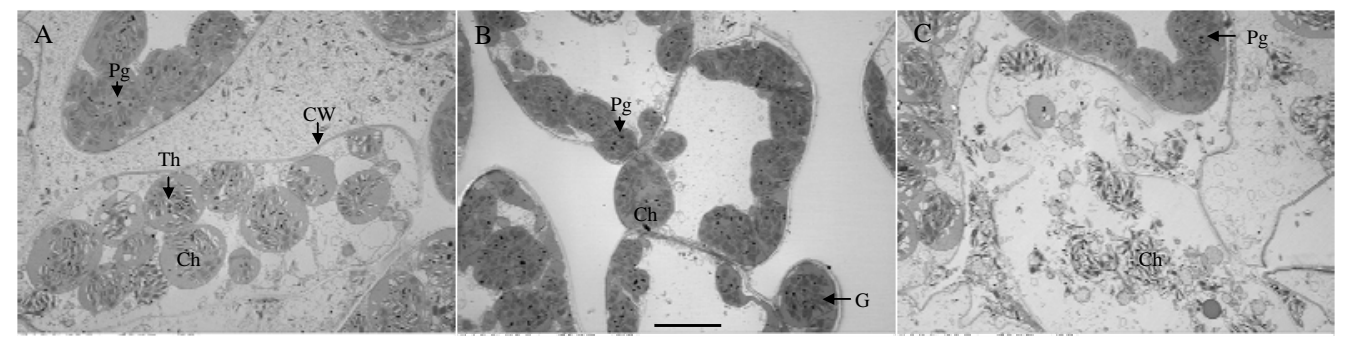

Fig. 2. Transmission electron micrographs showing the ultrastructure of the chloroplast at 16

DAM in flag leaves of control (A), half-degraining (B) and defoliation (C) treatments. Bars: $2 \mu \mathrm{m}$; Ch, chloroplast; CW, cell wall; G, granum; Mt, mitochondrion; Pg, plastoglobuli; Th, thylakoid.

\section{Antioxidant Enzyme Activity of Flag Leaf}

At 8 DAM, no significant difference in superoxide dismutase (SOD) activity of flag leaf was observed between half-degraining, defoliation and control. At 16 and 24 DAM, half-degraining significantly decreased the SOD activity compared with the control $(p<0.05)$. However, 
1 defoliation increased the SOD activity at $16(p>0.05)$ and $24(p<0.05)$ DAM (Fig. 3a). The

2 peroxidase (POD) activity exhibited the almost identical changing trend as SOD activity during

3 the period of 8 to 24 DAM (Fig. 3b). At 8 and 24 DAM, half-degraining significantly decreased

4 the catalase (CAT) activity with respect to the control $(p<0.05)$. The defoliation treatment

5 decreased the CAT activity at 8 DAM $(p<0.05)$, but caused sharp increases in the activity

6 thereafter and thus induced significantly enhancement of CAT activity 24 DAM $(p<0.05)($ Fig. 3c).

7 Even though the higher activities of these enzymes, especially at 24 DAM, the content of ROS

8 was still higher in flag leaf of defoliated plants. However, no difference in ROS content was

9 observed in flag leaf between half-degraining and intact plants (Fig. 3d). 


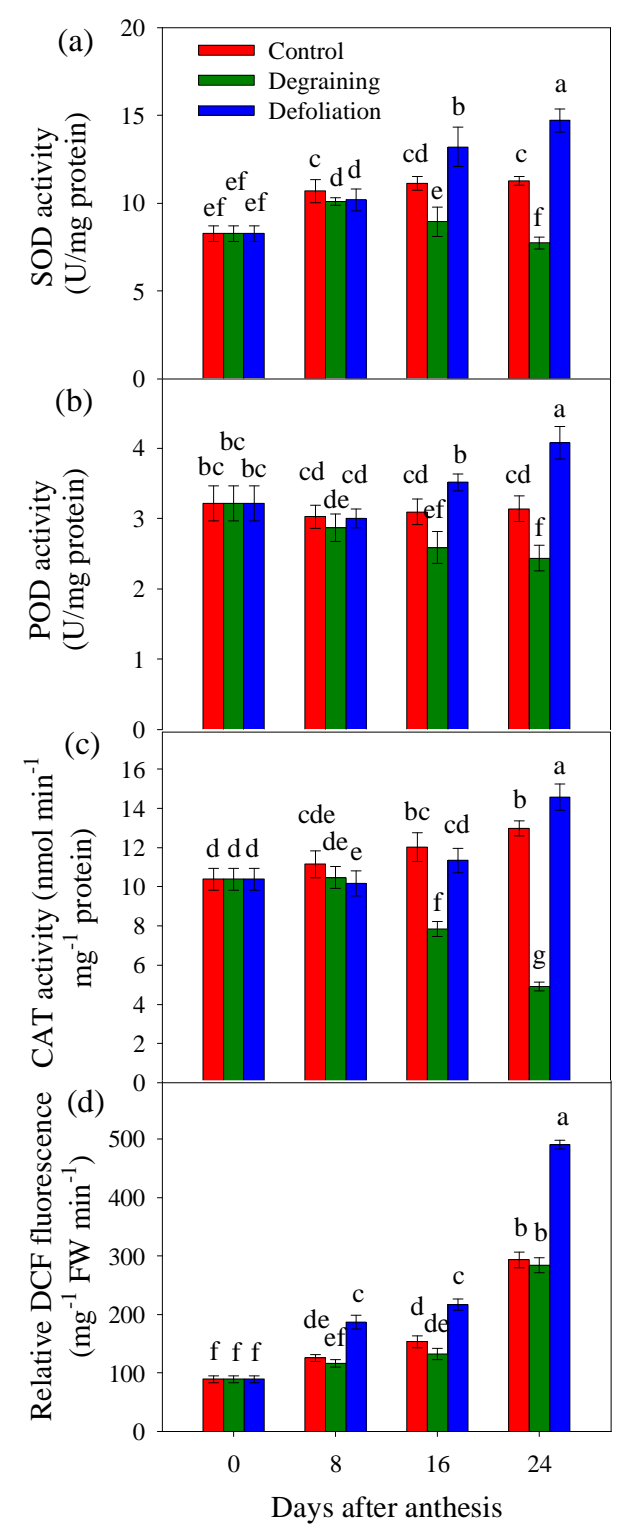

1

2 Fig. 3. Effects of sink-source manipulations on antioxidant enzyme activities and the relative

3 DCFH-DA fluorescence intensity of wheat flag leaves. Results are mean \pm SD.

4

5 Effect of Sink-Source Manipulations on Endogenous Hormones in Flag Leaves and

6 Grains

7 The total content of zeatin + zeatin ribuside + kinetin was used to evaluate the changes of CTKs

8 after manipulation. Both half-degraining and defoliation treatments decreased the CTKs content in 
1 flag leaf at $8(p<0.05), 16(p<0.05)$ and $24(p>0.05)$ DAM. However, the CTKs content decreased

2 in the remained grain of half-degrained plants at 8, 16 and $24(p<0.05)$; whereas it significantly

3 increased for defoliation at three time points. Interestingly, the ratio of grain to leaf CTK contents

$4 \quad$ was significantly decreased for half-degraining while significantly increased for defoliation (Table

$52)$.

$6 \quad$ No significant difference in flag leaf indoleacetic 3-acid (IAA) content was observed between

7 three treatments at 8 DAM. At 16 and 24 DAM, the highest level of the flag leaf IAA content was

8 observed in control, followed by significant decreases in half-degraining $(p<0.05)$ and further in

9 defoliation $(p<0.05)$ (Table 2). In grain, the IAA content increased for defoliation treatment at 8 ,

16 and 24 DAM $(p<0.05)$, while no difference was observed between control and half-degraining

treatment. As a result, the ratio of grain to leaf IAA contents was significantly increased for

half-degraining at 24 DAM and for defoliation at three time points (Table 2). In flag leaf,

half-degraining significantly decreased the $\mathrm{GA}_{3}$ content at 8, 16 and 24 DAM, but no difference

was observed between defoliation and control. In grain, both manipulations increased the $\mathrm{GA}_{3}$

content at 8, 16 and 24 DAM. Thus, both manipulations increased the ratio of grain to leaf IAA content (Table 2).

16 DAM and in grain at 8 DAM. Defoliation increased the free SA content in flag leaf during the 
1 half-degraining reduced the JA content at 8 and 16 DAM, while defoliation significantly enhanced

2 the JA content throughout the experimental time, resulting significantly increases in the ratio of

3 grain to leaf JA content for defoliation at three time points but similar between control and

4 half-degraining manipulation (Table 2).

5 Proteome Profiles of Wheat Flag Leaves and Grains under Different Sink-Source

6 Modifications

7 To investigate the proteome alterations of wheat flag leaves and grains due to different sink-source

8 modifications, iTRAQ-based quantitative proteomics analysis was conducted. Totals of the 2821

9 proteins in flag leaves and 2467 proteins in grains were identified reliably at a global FDR of $1 \%$. In

10 flag leaves of half-degrained plants, 97 proteins were assigned as differentially expressed

11 compared with intact plants, including 80 increased proteins and 17 decreased proteins. In flag

12 leaves of defoliated plants, 59 proteins were assigned as differentially expressed compared with

13 intact plants, including 54 increased proteins and 5 decreased proteins. In grains of half-degrained

14 plants, 115 proteins were assigned as differentially expressed compared with intact plants,

15 including 43 increased proteins and 72 decreased proteins. In defoliated plants, 121 proteins were

16 assigned as differentially expressed compared with intact plants, including 47 increased proteins

17 and 74 decreased proteins (Fig. 4; Table S1). 


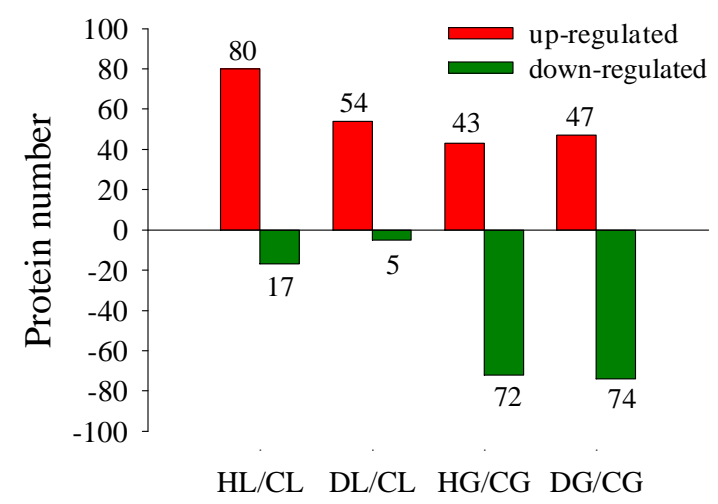

1

2 Fig. 4. Number of differential expressed proteins (DEPs) of different groups. HL, half-degrained

3 leaf; DL, defoliation leaf; CL, control leaf; HG, half-degrained grain; DG, defoliation grain; CG,

4 control grain.

5

\section{Gene Ontology (GO) Analysis}

7 To illustrate the major responsive processes in wheat flag leaves and grains, enrichment analysis

8 was performed on the GO ontology. The top 20 of the GO terms to them the DEPs clustered in the

9 biological process (BP), cell component (CC), and molecular function (MF) categories by GO analysis, respectively, is shown in Fig. 5.

11 In flag leaf, the BP analysis revealed that the DEPs identified in comparison of HL with CL were mainly classified into carbon fixation, oxidation-reduction process, organonitrogen compound metabolic process, carbohydrate biosynthetic process, starch biosynthetic process and etc. In MF analysis, the DEPs were classified into the organophosphate metabolic process, glyceraldehyde-3-phosphate metabolic process, glyceraldehyde-3-phosphate metabolic process, glucose 6-phosphate metabolic process, photosynthesis, carbohydrate derivative metabolic process, pentose-phosphate shunt, NADP metabolic process, cellular lipid metabolic process, 
1 single-organism metabolic process and etc. According to the CC analysis, half-degraining mainly

2 affected the chloroplast, plastid, cytoplasmic part, cytoplasm, chloroplast part, plastid part,

3 intracellular organelle, chloroplast envelope and chloroplast stroma (Fig. 5A; Table S2).

$4 \quad$ The BP analysis revealed that the DEPs identified in comparison of DL with CL were mainly

5 classified into organophosphate metabolic process, glyceraldehyde-3-phosphate metabolic process,

6 glucose 6-phosphate metabolic process, cellular aldehyde metabolic process, photosynthesis,

7 carbohydrate derivative metabolic process and etc. In the MF analysis, responses to the

8 half-degraining mainly included carbon-carbon lyase activity, phosphoenolpyruvate carboxylase

9 activity, phosphoenolpyruvate carboxykinase activity, carboxy-lyase activity, oxidoreductase

10 activity, ferredoxin:thioredoxin reductase activity and glutamate synthase (ferredoxin) activity.

11 Responses to defoliation mainly included electron carrier activity, proton-transporting ATPase

12 activity, hydrogen-exporting ATPase activity, hydrogen ion transmembrane transporter activity,

13 iron-sulfur cluster binding, tocopherol cyclase activity and glutaminyl-tRNA synthase

14 (glutamine-hydrolyzing) activity. Defoliation mainly affected chloroplast, plastid, chloroplast part,

15 plastid part, thylakoid part, thylakoid membrane, chloroplast envelope, organelle subcompartment and photosystem II (Fig. 5B; Table S2).

In grain, the BP analysis revealed that the proteins identified in $\mathrm{HG}$ compared with CG were mainly classified into organonitrogen compound metabolic process, cell wall macromolecule catabolic process, amino sugar catabolic process, defense response, aminoglycan metabolic process, amino sugar metabolic process, protein folding in endoplasmic reticulum and nucleoside metabolic process. In comparison of DG/CG, the majority of identified proteins were classified into CoA carboxylase activity, ligase activity, forming carbon-carbon bonds, biotin carboxylase 
1 activity, methylcrotonoyl-CoA carboxylase activity, acetyl-CoA carboxylase activity, starch

2 synthase activity, succinate dehydrogenase activity and etc. According to the CC analysis,

3 half-degraining mainly affected cytoplasm, cytoplasmic part, vacuole, apoplast, vacuolar

4 membrane, mitochondrial part, intracellular par and chloroplast thylakoid (Fig. 5C; Table S2).

5 For BP analysis, grain responses to defoliation mainly included organonitrogen compound

6 metabolic process, protein glutathionylation, protein folding in endoplasmic reticulum, pyridine

7 nucleotide metabolic process, oxidoreduction coenzyme metabolic process, L-proline

8 biosynthetic process, glucose 6-phosphate metabolic process, endosperm development and

9 others. In the MF analysis, responses to the defoliation mainly included glutamate 5-kinase

10 activity, glucokinase activity, glutamate-5-semialdehyde dehydrogenase activity, unfolded protein

11 binding, glucose-6-phosphate dehydrogenase activity, sucrose synthase activity, structural 
A
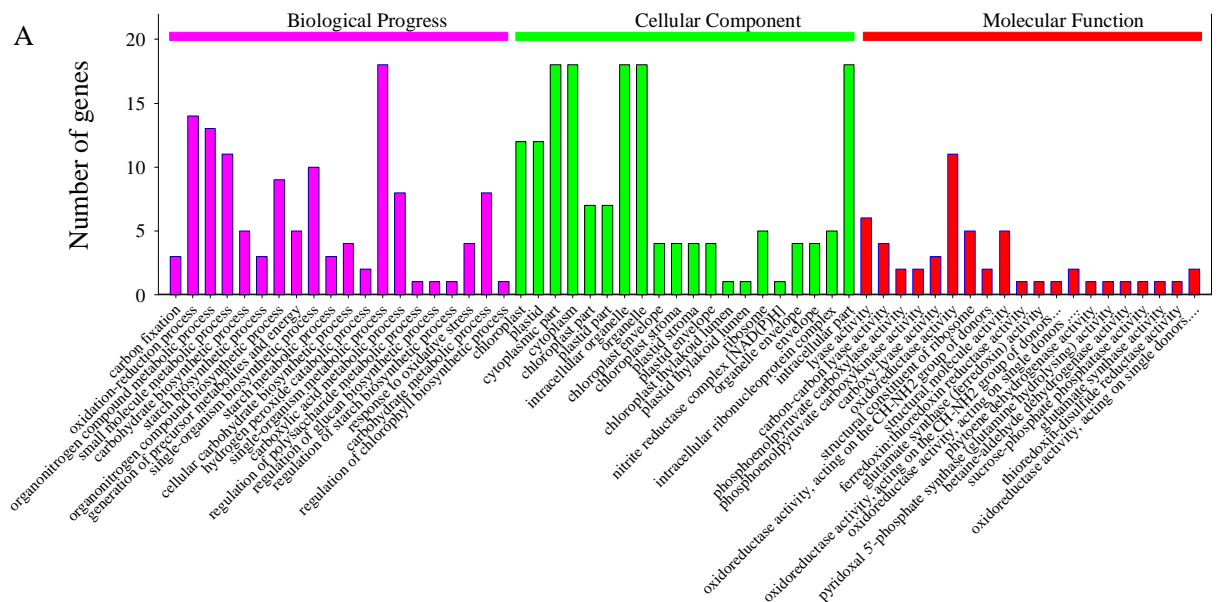

B

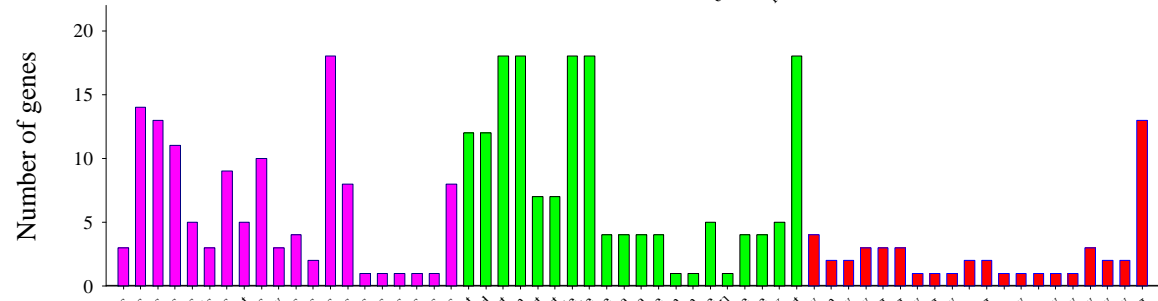

$\mathrm{C}$
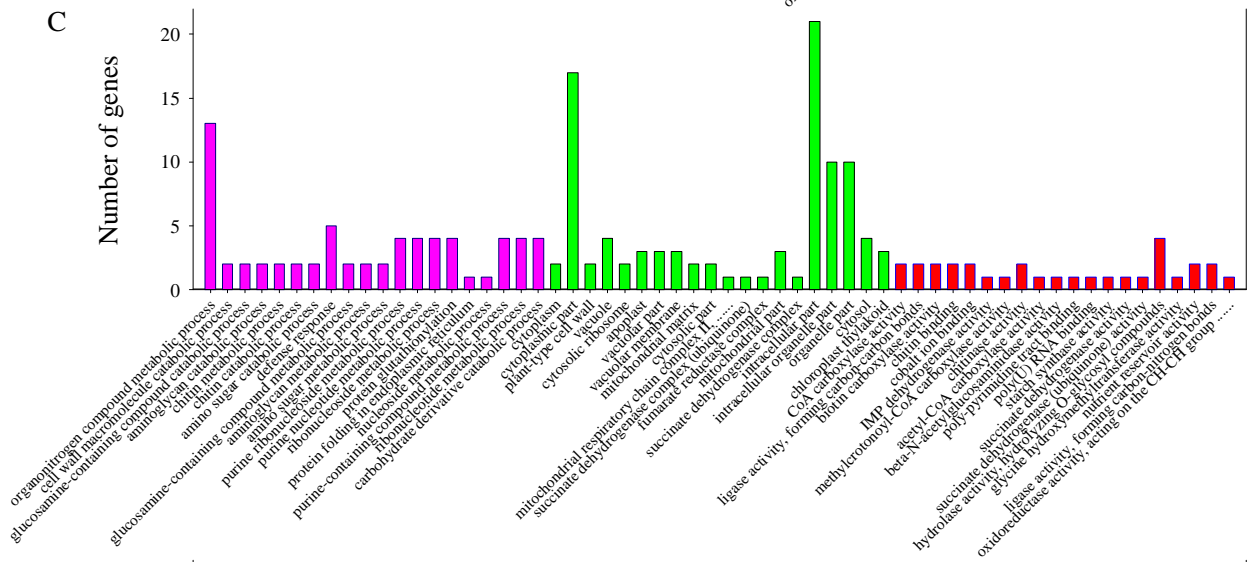

$\mathrm{D}$
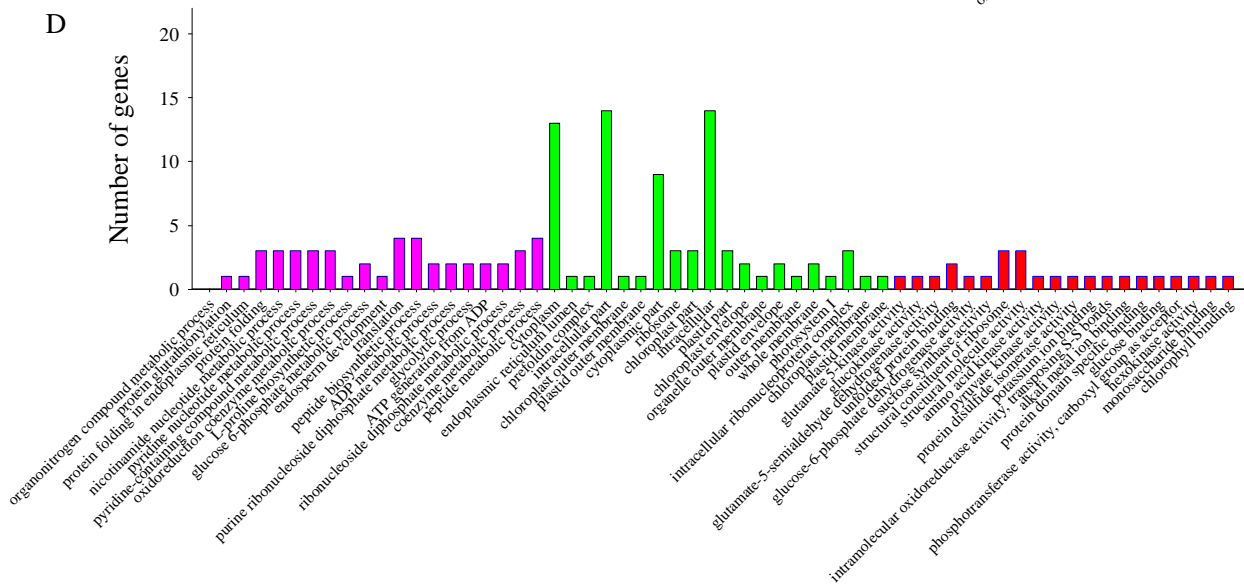
1 Fig. 5. GO annotation of DEPs in manipulated flag leaf and grain compared to control in

2 biological process, cellular component and molecular function. (A), Flag leaf: half-degraining vs

3 control; (B), flag leaf: defoliation vs control; (C), grain: half-degraining vs control; (D), grain:

4 defoliation vs control.

5

6 Kyoto encyclopedia of genes and genomes (KEGG) Pathway Analysis

7 To understand the major responses of cellular processes to sink-source modifications in wheat flag

8 leaves and grains, the KEGG pathway database was used with bases on the large-scale molecular

9 dataset. In the pathway enrichment analysis, DEPs in half-degrained flag leaves were significantly

enriched in linoleic acid metabolism and $\alpha$-linolenic acid metabolism (in lipid metabolism),

carbon fixation in photosynthetic organisms (in energy metabolism), nitrogen metabolism, carbon

metabolism and vitamin $\mathrm{B}_{6}$ metabolism. Whereas, DEPs in flag leaves of defoliated plants were

significantly enriched in photosynthesis, carbon metabolism, metabolic pathways, oxidative

phosphorylation, glyoxylate and dicarboxylate and metabolism (Fig. 6A). In grains of cycle), glycine, serine and threonine metabolism, glyoxylate and dicarboxylate metabolism and 
7

8

9
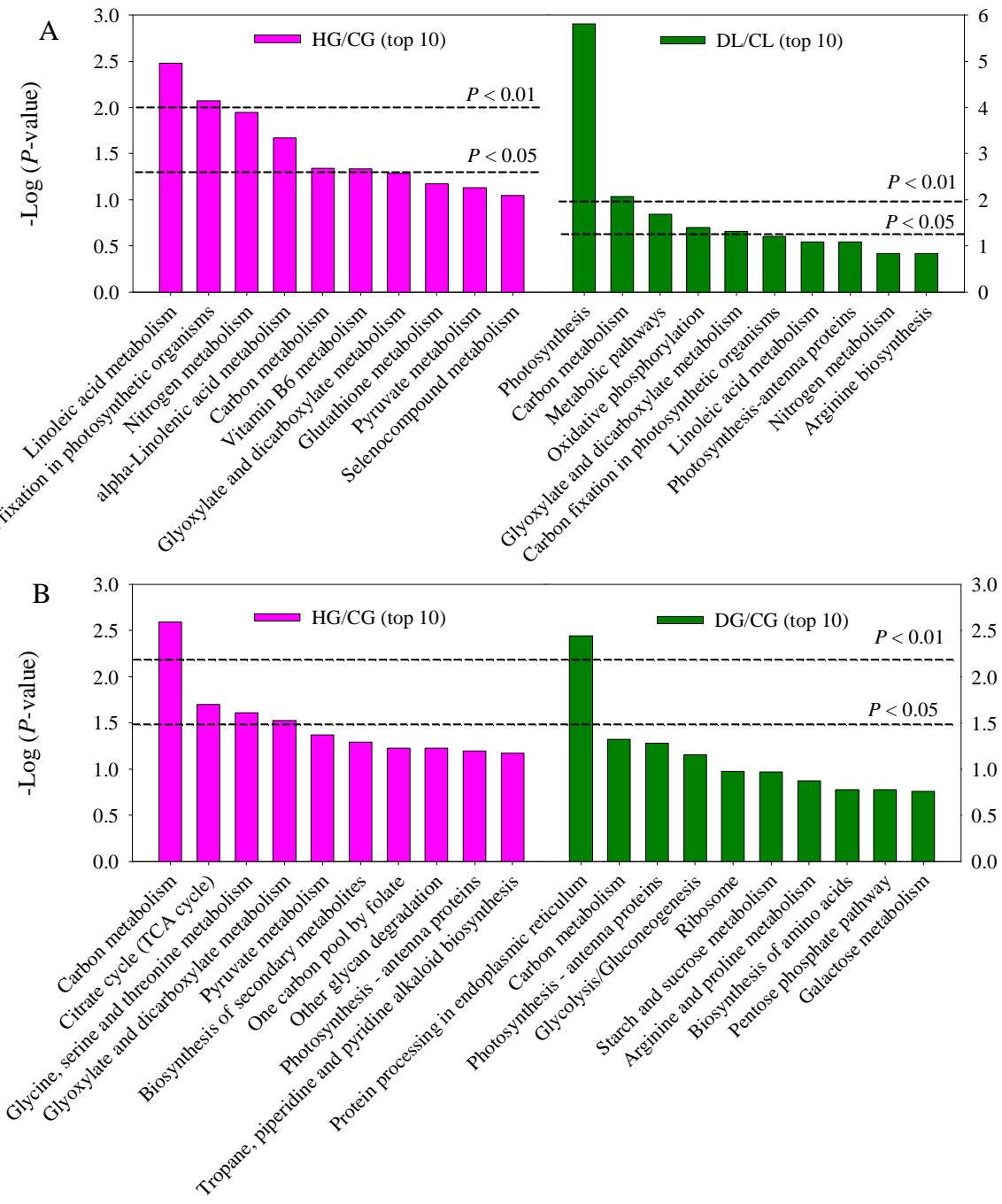

Fig. 6. The most significant associated KEGG pathways of DEPs for HL/CL (flag leaf of half-degrained group compared with control) and DL/CL (defoliated group compared with control) (A) and HG/CG (grain of half-degrained group compared with control) and DG/CG (defoliated group compared with control) (B).

\section{PPI Analysis of DEPs}

A regulation network of the DEPs identified in the current study was constructed to better 
bioRxiv preprint doi: https://doi.org/10.1101/647743; this version posted May 24, 2019. The copyright holder for this preprint (which was not certified by peer review) is the author/funder. All rights reserved. No reuse allowed without permission.

1 understand the relationship between the proteins and affected pathways. As shown in Fig. 7, a

2 complicated interaction network among DEPs was associated with the main biological processes.

A

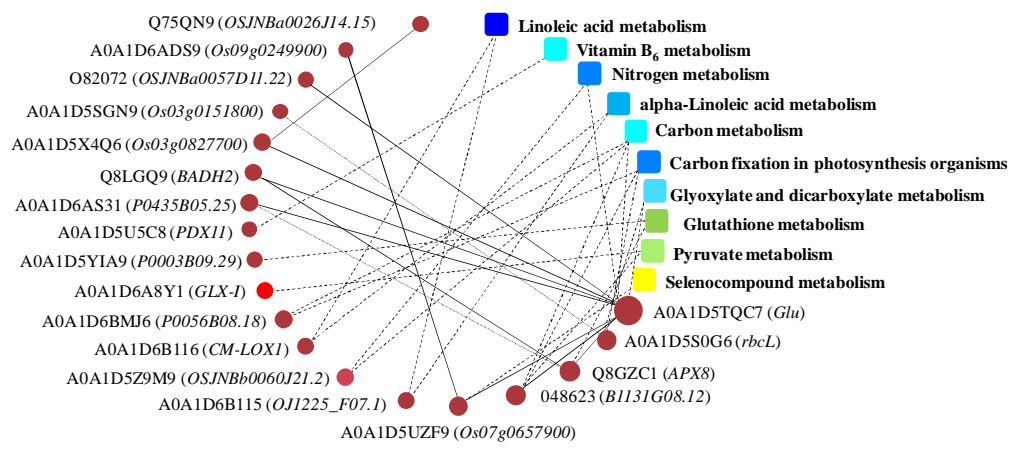

B

Q93XQ6 (B1331F11.9) P Photosynthesis

A0A1D6BRH4 (OsO3g0565200) Carbon metabolism

A0A1D6ARG9 (OSJNBb0065C04.47) Carbon metabolism

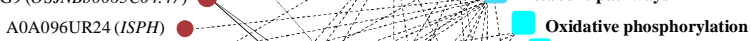

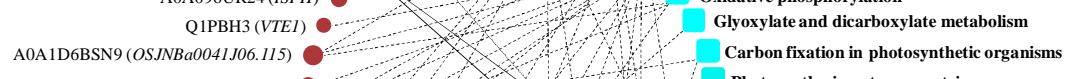

A0A1D6BSN9 (OSJNBa0041J06.115)

A0A1D6B115(CM-LOXI)

P46285 (OS.JNBa0042F21.13)

B2B9T8 $(O S 04 \mathrm{~g} 0137500)$

A0A1D6A852 (P0556A11.19)

A0A1D6A5B6 (B1267B06.4)

A0A1D5WFY6 (P0019E03.36)

A0A1D5SR31 (HXK5) A A0A1D5Z9M9 (OSJNBb0060J21.2)

W5EHIO (OsO3g0192400)

$\mathrm{C}$

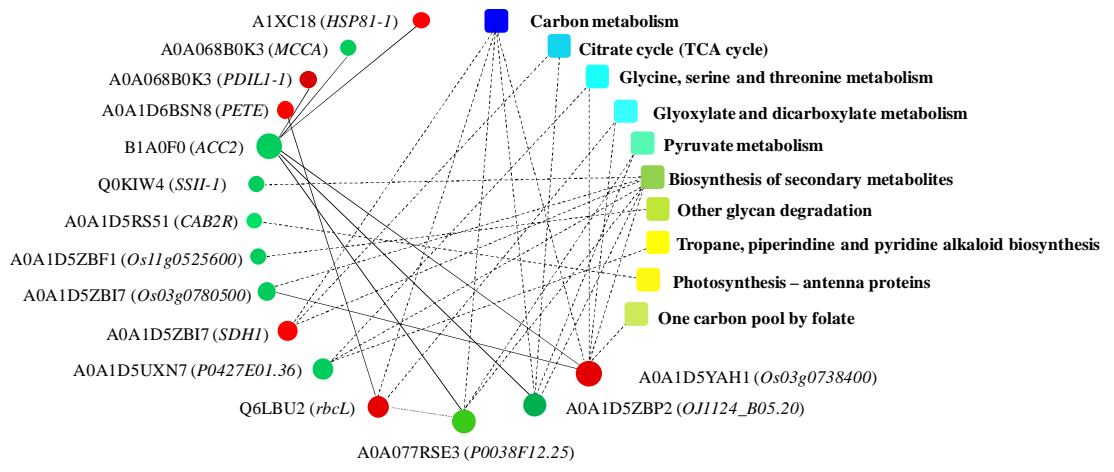

D

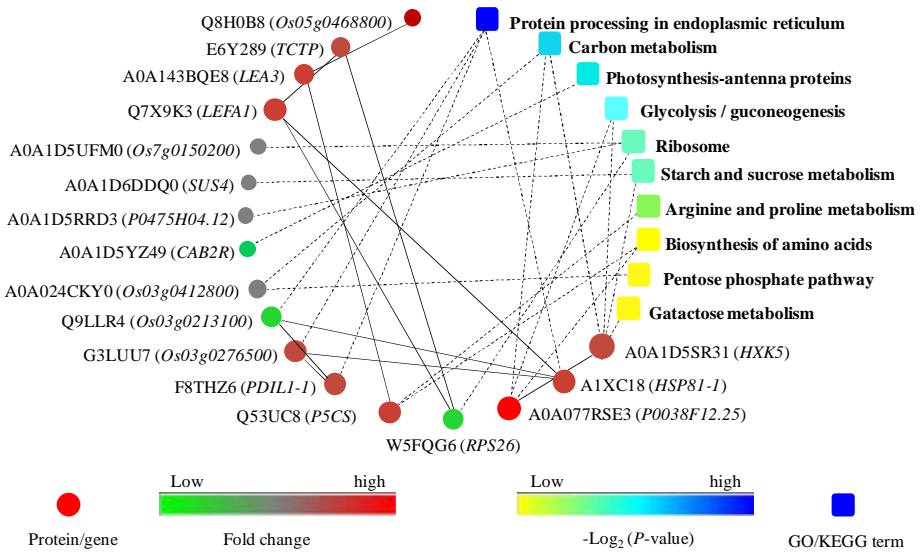

$4 \quad$ Fig. 7. Interaction networks of the differentially expressed proteins in flag leaf of degrained wheat 
1 plants. Circle nodes denote differentially expressed proteins (genes) and colored rectangle

2 indicates KEGG pathways. A solid line between two proteins indicates a known interaction

3 annotated in the database; a dashed line between proteins indicates a potential interaction.

4

5

6

8

9

All the proteins constructed into the model for HL/CL were up-regulated. Main interactions were observed between A0A1D5TQC7 (Glu, encoding $\beta$-1,3-glucanase) and O82072 (OSJNBa0057D11.22, encoding phosphoenolpyruvate carboxylase), A0A1D5X4Q6 (Os03g0827700, encoding ATP-dependent RNA helicase), and Q8LGQ9 (BADH2, encoding betaine-aldehyde dehydrogenase), A0A1D6AS31 (P0435B05.25) and Q8GZC1 (APX8, encoding thylakoid-bound ascorbate peroxidase (fragment)), which were involved in the carbon metabolism, nitrogen metabolism, carbon fixation in photosynthesis organisms and glyoxylate and dicarboxylate metabolism; between Q8GZC1 and Q8LGQ9, and A0A1D5TQC7, and A0A1D6AS31, which were involved in the glutathione metabolism; between A0A1D5UZF9 (Os07g0657900, thioredoxin reductase) and A0A1D6ADS9 (Os09g0249900, encoding ferredoxin-thioredoxin reductase, catalytic chain), and A0A1D5TQC7, which were involved in the selenocompound metabolism. Many other interactions were found between proteins but remained characterized.

All the proteins constructed into the model for DL/CL were up-regulated except A0A1D6BSN9 (PETE). Main interactions were observed between A0A1D5UAF0 (OJ1344_B01.16 encoding chlorophyll a-b binding protein) and A0A1D6ARG9 (OSJNBb0065C04.47, encoding peptidylprolyl isomerase), A0A1D6A5B6 (B1267B06.4, encoding putative oxygen-evolving enhancer protein 3-2, chloroplast (OEE3)), and 
1 A0A1D6BRX1 (ADI1, encoding ferredoxin) and A0A1D6BRH4 (Os03g0565200,

2 HAD-superfamily hydrolase), which were involved in the carbon metabolism and photosynthesis -

3 antenna proteins; between A0A1D5TCN3 (petC, encoding cytochrome b-c1 complex subunit

4 Rieske) and A0A1D6ARG9, and A0A1D6BRX1, and W5EHI0 (Os03g0192400, encoding

5 GRIM-19 family protein), and A0A1D6BSN9 (PETE, encoding plastocyanin), which were also

6 involved in photosynthesis and carbon metabolism. Many other proteins were classified into

7 biological functions including photosynthesis, oxidative phosphorylation, glyoxylate and

8 dicarboxylate metabolism and nitrogen metabolism (Fig. 7B).

9

The DEPs for HG/CG were constructed into the model (Fig. 7C). Main interactions were observed between A0A1D5YAH1 (Os03g0738400, encoding serine hydroxymethyltransferase) and A0A1D6BSN8 ((PETE, encoding plastocyanin), B1A0F0 (ACC2, encoding plastid acetyl-CoA carboxylase (fragment)) and A0A1D5ZBI7 (Os03g0780500, encoding succinate dehydrogenase [ubiquinone] flavoprotein subunit), which were involved in five KEGG pathways including carbon metabolism, glycine, serine and threonine metabolism, glyoxylate and dicarboxylate metabolism, biosynthesis of secondary metabolites and one carbon pool by folate; between A0A1D5ZBP2 (OJ1124_B05.20, encoding dihydrolipoamide acetyltransferase component of pyruvate dehydrogenase complex) and $\mathrm{B} 1 \mathrm{~A} 0 \mathrm{~F} 0$, which were involved in carbon metabolism, citrate cycle, glyoxylate and dicarboxylate metabolism and biosynthesis of secondary metabolites; between A0A077RSE3 (P0038F12.25, encoding pyruvate kinase) and Q6LBU2 ( $r b c L$, encoding rbcL gene product (30 AA) (fragment)), and B1A0F0, which was involved in three biological functions; between Q6LBU2 and A0A1D6BSN8, which was involved in two KEGG pathways. Many other proteins were classified into biological functions. 

phosphotransferase) and A0A077RSE3 (P0038F12.25, encoding pyruvate kinase), which were

7 involved in carbon metabolism, glycolysis/guconeogenesis, starch and sucrose metabolism and gatactose metabolism; among W5FQG6 (RPS26, encoding 40S ribosomal protein S26), E6Y289

9 (TCTP, translationally-controlled tumor protein) and Q7X9K3, which were involved in ribosome endoplasmic reticulum. Many other proteins were classified into biological functions (Fig. 7D).

\section{Enzyme Activities}

The activities of $\alpha$-amylase and $\beta$-amylase in flag leaves were higher during 8 to 24 DAM than 0

DAM and remained constant during 8 to 24 DAM. Overall, $\alpha$-amylase activity was lower than that of $\beta$-amylase. Compared with the intact plants, either half-degraining or defoliation did not affect the $\alpha$-amylase activity at 8 and 16 DAM, but at 24 DAM defoliation significantly increased while 
$1 \quad \beta$-amylase activity at 16 and 24 DAM (Fig. 8).

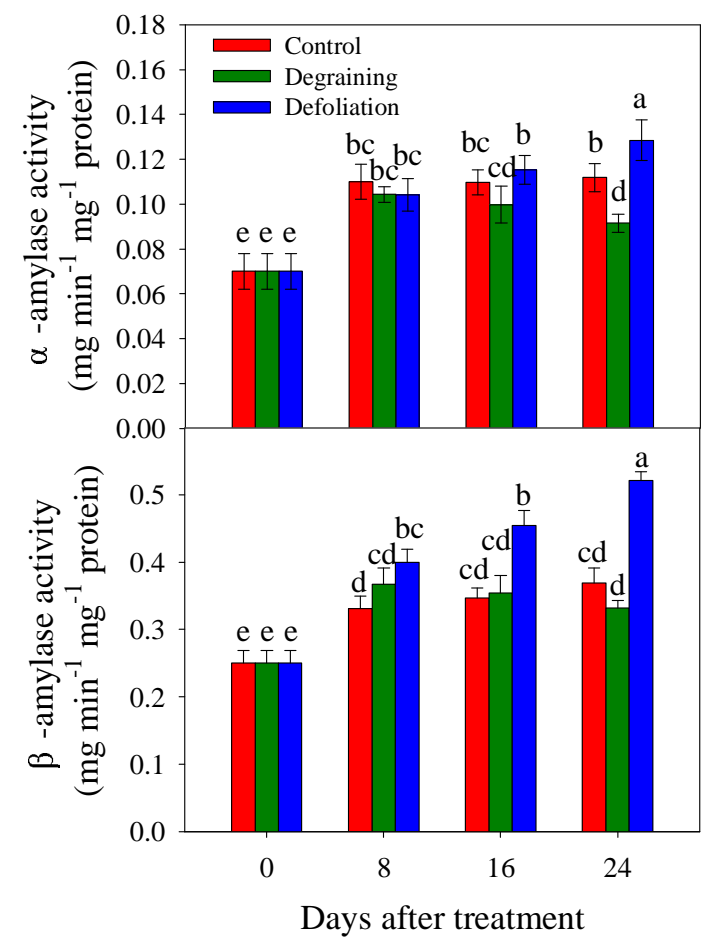

3 Fig. 8. Comparison of the activities of $\alpha$-amylase (a) and $\beta$-amylase (b) in flag leaf from the

4 half-degraining, defoliation and control. Each value represents the mean \pm SD from four

5 independent samples. The columns labeled with different letters are significantly different at $6 \quad p<0.05$ according to Duncan's test for multiple comparisons.

7

8

During the experiment time, the activities of NP, AKP and ACP (Fig. 9) in flag leaves of intact plants remained relatively constant. Detraining decreased the NP, AKP and ACP activity at 8, 16 and 24 DAM compared with the intact plants. Defoliation decreased the NP activity at 8, 16 and 24 DAM but significantly increased the AKP activity at 8,16 and 24 DAM and the ACP activity at 16 and 24 DAM. 


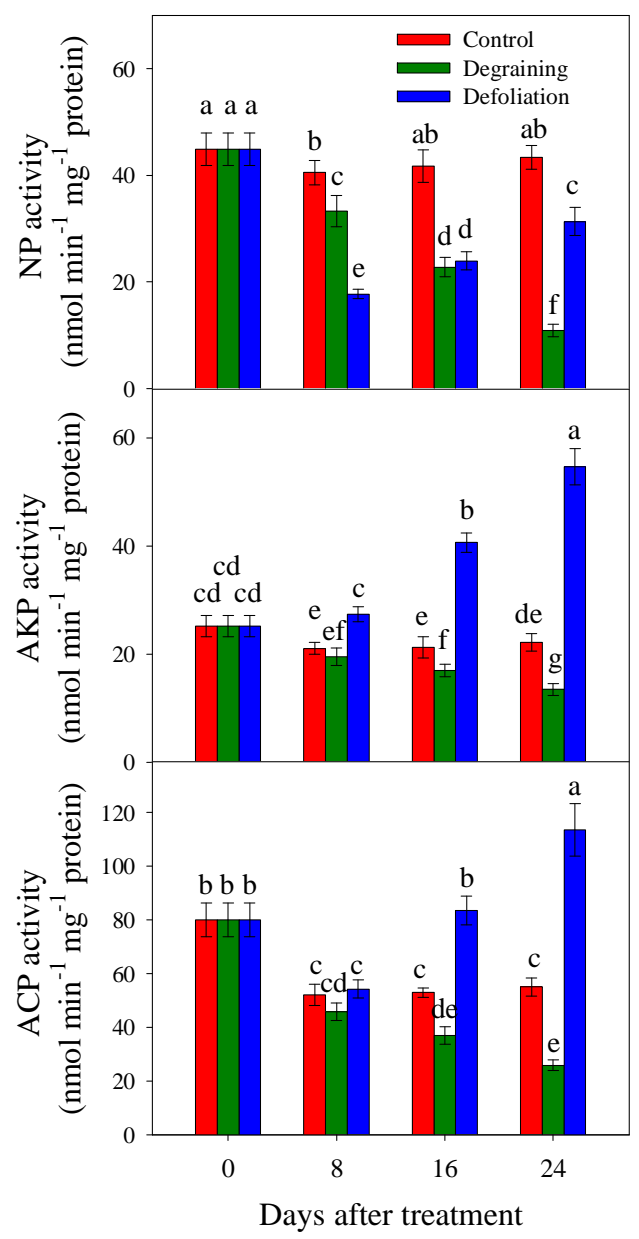

2 Fig. 9. Comparison of the activities of neutral proteinase (a), acid proteinase (b) and alkaline

3 proteinase (c) in flag leaf from the half-degraining, defoliation and control. Each value represents

4 the mean \pm SD from four independent samples. The columns labeled with different letters are

$5 \quad$ significantly different at $p<0.05$ according to Duncan's test for multiple comparisons.

\section{Grain Mass Responses to Half-degraining and Defoliation Manipulation}

8 The removal of spikelets on one side of the spikes potentially doubled the resources available to

9 the rest of the grains in the spikes; however, this manipulation did not halve the grain number per spike (Table 3). This de-graining increased the grain number per half-spike by $10.49 \%(p<0.05)$ 
1 and the single grain mass by $8.54 \%(p<0.05)$ compared with the in intact plants (control). As a

2 consequence, half-degraining increased the grain mass per half-spike by $19.92 \%$. Defoliation

3 reduced the grain number per half-spike by $16.37 \%(p<0.05)$. The grain mass significantly

4 responds to defoliation, causing reduction of the grain mass per half-spike by $19.64 \%(P<0.05)$.

\section{Discussion}

6 The source/sink interaction modulates the leaf senescence and photosynthetic efficiency (Jessica et

$7 a l ., 2008$ ) and thus determines the grain-filling rate and yield of cereals (Yang and Zhang, 2010). A

8 strong source with sufficient reserves is necessary for grain filling and high sink capability

9 promotes the reserve remobilization from source to sink (Fu et al., 2011). In the present study,

10 sink-source manipulations were used to investigate the roles of source-sink relationship in

11 regulation of leaf senescence and grain growth. Values of NDVI, PRI and SPAD and chlorophyll

fluorescence were determined at a single-leaf basis and we observed that half-degraining increased but defoliation decreased the levels of these indices compared to the intact control (Table 1 and

Fig. 1). Ultrastructural observations of flag leaf mesophyll cells at 16 DAM indicated that the mesophyll cells retained better for half-degraining (Fig. 2B) but inferior state for defoliation of the integrated chloroplasts (Fig. 2C). The NDVI, PRI and SPAD are the most frequently used spectral indices and are associated with chlorophyll contents and leaf senescence in higher plants (Chen and Chen, 2008). Chlorophyll fluorescence and chlorophyll degradation were also widely used as typical markers of developmental senescence progression and photosynthesis (Kong et al., 2010, 2017; Lyu et al., 2017; Kang et al., 2018). Higher values of them were closely associated with the grain yield (Vicente et al., 2018). The evidence from our physiological analysis and the 
1 later but defoliation cause earlier leaf senescence.

2 It is well known that plant senescence is initiated and accelerated by active oxygen or free

3 radicals. Antioxidant enzymes, such as SOD, POD and CAT, play important roles in scavenging

4 excess ROS and reducing ROS detrimental effects on the cellular membrane. In wheat, the

5 competence of the antioxidant defense system contributes the delayed senescence (Hui et al.,

6 2012). The present study, the ROS content were higher in defoliated flag leaf than that of intact

7 plants, although the defoliation significantly increased the activities of SOD, POD and CAT in the

8 flag leaves, especially at 24 DAM. In DEPs identified using iTRAQ analysis, SOD (Fragment)

9 was upregulated in defoliated plants at 16 DAM (Table S1). These results indicate that partial

source removal may induce more active physiological responses and thus cause a burst of ROS

11 and membrane oxidation which in turn result in the premature senility of the wheat plants. The

increased activity of these antioxidant enzymes may be a strategy to protect plant from more

serious damage, partially relieve the plant senescence and attempting to increase the active

SOD, POD and CAT decreased but the ROS content also slightly decreased (Fig. 3; Table S1 for

POD), indicating that half-degraining lay a lower "burden" to flag leaf and lower ROS production. 
1 senescence (Xu and Huang, 2007; Reguera et al., 2013; Jan et al., 2019) and closely associated

2 with the progress of leaf senescence in the stay-green mutant tasgl of wheat (Wang et al., 2016)

3 and in the stay-green phenotype of maize (Zea mays L.) (He et al., 2005). The grain CTK

4 concentrations were significantly and positively correlated with the grain-filling rate and

5 maximum grain mass (Yang et al., 2002; Yang et al., 2008; Zhang et al., 2009). In rice (Oryza

6 sativa L.), wheat, maize and barley (Hordeum vulgare L.), a higher CTK concentration was

7 generally observed in the endosperm of the grains and involved in cell division during the early

8 phase of grain development which, in combination with functions of auxin, are positively and

9 significantly correlated with cell division, sink strength and the grain-filling rate (Dietrich et al.,

1995; Yang et al., 2000; Zhang et al., 2016; Xu et al., 2007; Zhang et al., 2009a; Liu et al., 2016;

Yang et al., 2016), due to the enhanced sink strength (Rijavec et al., 2009; Yu et al., 2015).

High IAA concentrations in the grains could create an "attractive power", leading to an increase in CTK concentrations in grains (Seth and Waering, 1967; Singh and Gerung, 1982). Lur and Setter (1993) reported that grain IAA content rapidly increased in maize at nearly grain filling, nutrient assimilation and source nutrient remobilization (Kong et al., 2015). In cucumber, leaf auxin promotes source $\mathrm{N}$ remobilization during the reproductive stage (Du et al., 2018). 
1 2006; Suzuki et al., 2012).

2 In the present study, we observed that defoliation decreased the contents of CTKs and IAA in

3 flag leaf (except at 8 DAM); however, this manipulation significantly increased the contents of

4 CTKs, IAA and $\mathrm{GA}_{3}$ in grain and thus increased the grain/leaf ratio of CTKs, IAA and GA 3

5 contents. Based on the results from current and previous studies, we postulate that higher source

6 completion due to defoliation stimulate the hormone biosynthesis, thereby trying to increase sink

7 strength and enhancing their potential to absorb more of the carbohydrate transported from the

8 limited source. Meanwhile, decreased levels of CTKs and IAA for defoliation promote the

9 degradation of large molecules for grain filling, which cause early senescence as demonstrated by

10 ultrastructural observation and measurement of vegetation indices (Table 1; Fig. 2). This view is

11 highly consistent with the findings that in cultivar with relative large sink ratio exists a greater

competition for source photosynthate supply to meet the grain filling, leading to premature

senescence of the plant (Yang and Zhang, 2010). Furthermore, the data presented here suggest that

that the ratio of grain to leaf CTK, IAA and $\mathrm{GA}_{3}$ contents may be the decisive factor in regulating

leaf senescence in wheat.

effect on that in grain, and decreased $\mathrm{GA}_{3}$ content in flag leaf but significantly increased the $\mathrm{GA}_{3}$ 
1 defoliation, the lower ratio of grain to leaf CTK content may contribute the delayed leaf

2 senescence for half-degraining. As for $\mathrm{GA}_{3}$, the lower content was consistent with the decreased

$3 \alpha$-amylase activity in flag leaf and higher $\mathrm{GA}_{3}$ stored in the grain may be favorable for its

4 germination.

5 SA, JA, CTKs and other hormones are the major hormones that have antagonistic and

6 synergistic signaling effects on plant senescence (Thomas and Ougham 2014). Accumulation of

7 ROS and JA lead to early leaf senescence and low photosynthesis efficiency (Wang et al., 2015).

8 Specific inhibition of JA biosynthesis in the leaf resulted in grain yield increase in rice (Tamaki et

9 al., 2015). The connection between leaf senescence and SA is still unclear. However, increasing

body of evidence has demonstrated that SA in wheat act as a signaling molecule to induce an

11 endogenous ROS detoxification, increases the activities of SOD, CAT, APX and glutathione reductase, help preserve photosynthetic function in stresses (see review by Abhinandan et al., 2018). In our study, we observed that in flag leaf, defoliation increased the free SA but decreased the JA content during experimental period. While in grain, exactly reverse effects of both manipulations on SA and JA levels were observed (Table 2). The current results indicate that antagonistic action between JA and SA may exist in regulating leaf senescence and grain filling, and the significantly higher SA/JA ratio (data not shown) may help to protect plant from too early 
1 Leaf senescence is associated with fundamental changes in the proteome. In the present study,

2 a comparative proteome analysis based on ITRAQ was performed to identify the critical candidate

3 factors involved in leaf senescence and grain filling. GO terms within the biological process

4 category, the molecular function category and cellular components were showed in Fig. 5. KEGG

5 pathway enrichment analysis of these genes and PPI were also performed (Fig. 6).

6 The destruction of the oxidation-reduction system is accompanied by an increase in burst of

7 ROS such as superoxide $\left(\mathrm{O}^{2-}\right)$ and hydrogen peroxide $\left(\mathrm{H}_{2} \mathrm{O}_{2}\right)$, which may lead to early leaf

8 senescence (Li et al., 2014; Parihar et al., 2015). Glutathione metabolism can reduce and eliminate

9 oxidative damage caused by ROS plays an important role in maintaining redox balance (Hicks et

10 al., 2007). In this pathway, glutathione is recycled through the oxidation/reduction process and

11 thus involved in oxidative stress. Ferredoxin:thioredoxin reductase can acts as one component of

antioxidative defence systems (Geigenberger et al., 2017) and was required for proper chloroplast

development and was involved in the regulation of plastid gene expression in Arabidopsis thaliana

14 (Wang et al., 2014). In DEPs of our study, ferredoxin:thioredoxin reductase was upregulated in

the half-degraining leaf and was clustered into the MF. The chloroplast is the central organelle that

produces ROS, whereas accumulation of ROS may cause oxidative damage and inhibit

17 photosynthesis (Exposito-Rodriguez et al., 2017). In comparison between HL and CL group, the

most prevalent GO terms for BP were involved in the ROS metabolic processes, such as

oxidation-reduction process, $\mathrm{H}_{2} \mathrm{O}_{2}$ catabolic process, response to oxidative stress, $\mathrm{H}_{2} \mathrm{O}_{2}$ metabolic

20 process, $\mathrm{O}^{2-}$ removal and so on (Table $\mathrm{S} 1$ ). In these processes, the homeostasis of

PAS_Zscore and oxidoreductase activity (MF) and activities of several kinds of oxidoreductase 
1 (MF) were significantly affected, which may occur in the chloroplasts as indicated in the CC

2 analysis (Fig. 5A) and glutathione metabolism was constructed to the top 10 of KEGG pathways

3 for HL/CL. In MF analysis for HL/CL, phytoene dehydrogenase acitivty was significantly affected,

4 which was associated with carotenoid biosynthetic pathway, serve as membrane integrated

5 antioxidants, protecting cells from oxidative stress (Liu et al., 2012). The thylakoid-bound

6 ascorbate peroxidase (Fragment) and betaine aldehyde dehydrogenase were important factors in

7 abiotic stresses and can also function as a ROS scavenger (Golestan Hashemi et al., 2018) and

8 both were involved in many pathways as indicated in PPI analysis (Fig. 7) and upregualted in flag

9 leaf of half-degrained plants (Table S1). These results imply that half-degraining may enhance

10 antioxidant ability by promoting ROS scavenging activities and at least partially contributed to

11 higher chlorophyll content (as indicated by higher SPAD values) and delayed leaf senescence.

12 KEGG pathway analysis for HL/CL suggested that the DEPs were mainly involved in linoleic

13 acid metabolism (lipoxygenase, up-regulated), nitrogen metabolism (such as upregualted

14 biological process organonitrogen compound metabolic process and organonitrogen compound

15 biosynthetic process). Correspondingly, MFs including glutamate synthase activity, glutamate

16 synthase (ferredoxin) activity and pyridoxal 5'-phosphate synthase (glutamine hydrolysing)

17 activity were affected and carbon metabolism (carbohydrate biosynthetic process, starch

18 biosynthetic process, starch metabolic process, cellular carbohydrate biosynthetic process,

19 carbohydrate metabolic process, carboxylic acid metabolic process. The MFs such as

20 phosphoenolpyruvate carboxylase activity, phosphoenolpyruvate carboxykinase activity,

21 sucrose-phosphate phosphatase activity were affected (Table S1). Of the most interesting, sucrose

22 phosphate phosphatase was associated with source activity, enhancing transport of its resulting 
1 product sucrose from the photosynthetic tissues via the phloem into sink (Maloney et al., 2015)

2 and thus affecting progress of leaf senescence in wheat (Wang et al., 2016). BP analysis showed

3 that these processes were upregulated, indicating that in half-degrained flag leaf, nitrogen and

4 carbon metabolism may be enhanced.

5 As for the cellular component, categories playing important roles in protein biosynthesis such

6 as the cytosolic ribosome and ribosome were highly represented in DL (Fig. 5C; Table S2).

7 Accordingly, DEPs such as 60S ribosomal and $40 \mathrm{~S}$ ribosomal proteins were upregualted (Table

$8 \mathrm{~S} 1)$.

9 At the same time, DEPs related with photosynthesis (carbon fixation) and generation of 10 precursor metabolites and energy that occur in the thylakoid, plastid) were upregualted (Table S1).

11 For example, phosphoenolpyruvate carboxylase was upregulated, which showed an significant interaction with carbon fixation in photosynthesis organisms (Fig. 7).

In the grains of half-degrained plants, amine oxidase (DEPs, A0A1D5UXN7, A0A1D5UXN8,

A0A1D5UXN9, A0A1D6DCS6), which catalyzes the reaction to produce $\mathrm{H}_{2} \mathrm{O}_{2}$, was down-regulated and the MF of primary amine oxidase activity (GO:0008131) was affected.

Superoxide dismutase [Cu-Zn] (A0A1D5TQL0, A0A1D5TQL1, A0A1D5TQL3, W5B1E5) and

GO:0016721, GO:0016641, GO:0016864, GO:0016638) were also affected. Protein

The significantly affected KEGG pathways mainly included the carbon and nitrogen 
1 metabolism. However, nearly all the nitrogen- and carbon-related in the top 20 of BP were

2 inhibited (Table S2). Most of biological processes related to metabolites and energy were

3 significantly downregualted. This response indicates that low levels of carbohydrate (derivatives)

4 are needed to be processed in the grains of half-degrained plants.

5 Protein disulfide isomerases (PDIs) are enzymes found primarily in the endoplasmic reticulum

6 (ER) in eukaryotes play a vital role in protein folding. The up-regulated levels of PDIs

7 (A0A024FRN3, A0A1D5XQP7, A0A1D5XQP9, B9A8E3, F8THZ6, Q6JAB5, Q93XQ8) in the

8 present study indicated the higher PDI activity (MF) and confirmed the active status of protein

9 synthesis (Hayano et al., 1995; Lv et al., 2016; Kayum et al., 2017) and higher resistance to

abiotic stresses (Kayum et al., 2017). This conclusion was strongly confirmed by the upregulation

11 of 60S ribosomal protein L29 (A0A1D5RRD3), 40S ribosomal protein S12 (A0A1D5UFM0,

A0A1D5UVS7) and Eukaryotic translation initiation factor 4B1 (Q9AUJ7) (Table S1).

In plants, acetyl-CoA carboxylase activity is found in the plastids and catalyzes the first malonyl-CoA (Fazli et al., 2005; Liu et al., 2007; Lv et al., 2016). In the present study, acetyl-CoA carboxylase (Q8L4W1), plastid acetyl-CoA carboxylase (fragment) (A0A068B0K3, A0A068B0L8, A0A068B0M7, A0A068B226, A0A068B2H1, A0A068B2I1, A0A068B3I5, activity (GO:0016421), acetyl-CoA carboxylase activity (GO:0003989) and biotin carboxylase activity (GO:0004075) were affected. In PPI analysis, B1A0F0 (ACC2) showed interactions with 
1 were affected (Fig. 7).

2 Processes involved in photosynthesis such as photosynthesis (GO:0015979), photosynthesis

3 and light reaction (GO:0019684), photosynthesis, light harvesting (GO:0009765) and

4 photosynthesis, dark reaction (GO:0019685) were also significantly up-regulated in the grain of

5 degrained plants, indicating that higher use efficiency of light, $\mathrm{CO}_{2}$ and supplication of higher

6 amount of $\mathrm{O}_{2}$ to the developing endosperm (Kong et al., 2016). In addition, interaction of

7 plastocyanin (A0A1D6BSN8) with rbcL gene product (30 AA) (fragment) (Q6LBU2) was

8 observed and both DEPs were upregulated, indicating that carbon metabolism and glyoxylate and

9 dicarboxylate and metabolism were enhanced (Fig. 7).

In the molecular function category, processes was involved in succinate dehydrogenase activity (GO:0000104) and succinate dehydrogenase (ubiquinone) activity (GO:0008177) (Fig. mitochondrial respiratory chain complex II (GO:0005749), succinate dehydrogenase complex (ubiquinone) (GO:0045257) (Fig. 5C). In addition, GMP biosynthetic process (GO:0006177) and GMP metabolic process (GO:0046037) were significantly represented. In the molecular function category, processes involved in hydrolase activity (hydrolyzing O-glycosyl compounds) 
1 In our study, relative ROS content increased in defoliated flag leaf (Fig. 3), which may inhibit

2 photosynthesis (Exposito-Rodriguez et al., 2017) as discussed above. However, in defoliation

3 plants glutathione s-transferase (W5E8I6), superoxide dismutase (Fragment) (A3FKE5),

4 oxidoreductase activity, acting on superoxide radicals as acceptor (GO:0016721), superoxide

5 dismutase activity (GO:0004784) (Fig. 3), oxidation-reduction process (GO:0055114),

6 oxidoreduction coenzyme metabolic process (GO:0006733) (Table S2) the tocopherol cyclase

$7 \quad(\mathrm{Q} 1 \mathrm{PBH} 3)$ and glutathione S-transferase (W5E8I6) and thus tocopherol cyclase activity

8 (GO:0009976) were upregulated, indicating that in the flag leaf of defoliated plants, some

9 strategies were developed to eliminate oxidative damage caused by ROS (Kanwischer et al., 2005;

10 Liang et al., 2018). However, these means can only partially compensate for the ROS burst,

11 because the overall capability of ROS metabolic process (GO:0072593), removal of superoxide

radicals (GO:0019430), cellular response to superoxide (GO:0071451, GO:0000303), cellular

response to oxygen radical (GO:0071450, GO:0000305), regulation of $\mathrm{H}_{2} \mathrm{O}_{2}$ metabolic process

(GO:0010310) and cellular response to ROS (GO:0034614) were downregulated (Table S2).

Interestingly, the top 50 significantly represented BPs were upregulated in flag leaf of 
1 downregulated (Table S2). As a consequence, the net photosynthetic efficiency decreased (Fig.

2 5B). These changes occurred in chloroplast (CC). In MF analysis, iron-sulfur cluster binding,

$32 \mathrm{Fe}-2 \mathrm{~S}$ iron-sulfur cluster binding and $3 \mathrm{Fe}-4 \mathrm{~S}$ iron-sulfur cluster binding play an important role in

4 photosynthetic rate by regulating electron transfer and chlorophyll content in rice (Zhao et al.,

5 2015), however, these GO terms were significantly affected and thereby influencing electron

6 carrier activity, proton-transporting ATPase activity, rotational mechanism, hydrogen-exporting

7 ATPase activity, hydrogen ion transmembrane transporter activity, ATPase activity,

8 plastoquinol-plastocyanin reductase activity (located in plastid and chloroplast thylakoid

9 membrane). These functions were closely coupled to transmembrane movement of ions, rotational

10 mechanism, monovalent inorganic cation transmembrane transporter activity, electron transporter,

11 transferring electrons from cytochrome $b 6 / f$ complex of photosystem II activity (Fig. 5B). The

12 plastoquinol-plastocyanin reductase activity (GO:0009496) and electron carrier activity and

13 electron transporter, transferring electrons from cytochrome b6/f complex of photosystem II

14 activity (GO:0046028) that are located in the chloroplast cytochrome b6- $f$ complex (GO:0009512)

15 enables the directed movement of electrons from the cytochrome $b 6 / f$ complex of photosystem II

16 and couples the energy released from electron transport to proton translocation across the

17 membrane. Therefore, these results indicate that in the flag leaf of defoliated plants, energy supply

18 may be very important. Indeed, The GO categories enriched are primarily related to energy

19 metabolism were upregulated, including glyceraldehyde-3-phosphate metabolic process

20 (GO:0019682), glucose 6-phosphate metabolic process (GO:0051156) and carbohydrate derivative

21 metabolic process (GO:1901135) and generation of precursor metabolites and energy,

22 pentose-phosphate pathway, pentose-phosphate shunt). 
1 The accumulation of peptidyl-prolyl cis-trans isomerase (Q93XQ6), peptidylprolyl isomerase

2 (A0A1D6ARG9) mediates protein folding (GO:0006457) and interacts with chlorophyll a-b

3 binding protein and cytochrome b-c1 complex subunit Rieske (Fig. 7), thus promoting the

4 functions of these proteins. As for lipid metabolism, organophosphate metabolic process

5 (GO:0019637), cellular lipid metabolic process (GO:0044255, GO:0006629), lipid biosynthetic

6 process (GO:0008610) and phospholipid biosynthetic process (GO:0008654, GO:0006644) were

7 also upregulated.

8 In defoliated grain, protein glutathionylation (GO:0010731), a mechanism for redox regulation

9 and signaling (Gallogly and Mieyal, 2007), and oxidation-reduction process (GO:0055114) were

10 downregulated in the current study, indicating a decrease in the ability to scavenge ROS.

11 In the BP category analysis, organonitrogen compound metabolic process (GO:1901564) and cellular protein metabolic process (GO:0044267) were enhanced, which may be consistent with the increases in proteinase activities (Fig. 9). However, protein folding in endoplasmic reticulum (GO:0034975), protein folding (GO:0006457) were downregulated (Fig. 5); accordingly, protein processing in endoplasmic reticulum was significantly affected (Fig. 6) was downregulated. sec61p (Q9LLR4) In further, translation (GO:0006412), peptide biosynthetic process (GO:0043043), peptide metabolic process (GO:0006518), and L-proline biosynthetic process (GO:0055129, GO:0006561) were downregulated. Accordingly, a large number of low molecular weight glutenin (subunits) were decreased (Table S2). These processes may occur in endoplasmic reticulum lumen (GO:0005788), prefoldin complex (GO:0016272) and ribosome (GO:0005840), regulating structural constituent of ribosome (GO:0003735) (Table S2). 
1 metabolites and energy (GO:0006091) were downregulated. Meanwhile, pyruvate kinase

2 (A0A077RSE3, A0A1D5WW05, A0A1D5WW06, A0A1D6RQH6) (Table S1) and thus pyruvate

3 kinase activity (GO:0004743) decreased, suggesting that energy generation was decreased in the

4 grain of defoliated plants.

5 Chlorophyll a-b binding protein, chloroplastic (A0A1D5YZ49, A0A1D5YZ50, A0A1D5ZLT0,

6 A0A1D6S1V3) was downregulated. Moreover, photosynthesis, light harvesting (GO:0009765)

7 and photosynthesis, light reaction (GO:0019684) were also decreased. These processes might

8 occur in the chloroplast parts (GO:0009707, GO:0044434, GO:0009941, GO:0031969). These

9 results were consistent with the decrease in photosynthetic efficiency (Fig. 1).

From these results, we surmised that defoliation might have aggravated the premature

senescence of the wheat plants and ultimately, endosperm development (GO:0009960,

GO:0048316), seed development (GO:0048316) and seed maturation (GO:0010431, GO:0010431)

13

14

were inhibited.

A large amount of macromolecules in normal senescent leaves are degraded into small molecules by degradation enzymes (Buchanan-Wollaston et al., 2003). The translocation of non-structural carbohydrates in leaf to grain are essential for growing grains, which was closely correlates with senescence (Smith et al., 2005). Starch is the main carbohydrates and primarily hydrolyzed by a- and $\beta$-amylase. Genes encoding proteases to hydrolyze proteins show highly induced expression during leaf senescence in different species (Liu et al., 2008; Desclos et al., 2009; Hollmann et al., 2014; Moschen et al., 2016). At least a portion of senescence-associated proteases localize to senescence-associated vacuoles to degrade chloroplast-derived proteins and are up-regulated during leaf senescence and then the resulting catabolic products are mobilized from 
1 leaves to the developing seeds (Drake et al., 1996; Buchanan-Wollaston et al., 2003; Carrión et al.,

2 2013; Li et al., 2017). In the present study, defoliation increased the activities of a-amylase,

$3 \quad \beta$-amylase (Fig. 8), acid proteinases and alkaline proteinases (Fig. 9) but decreased the activity of

4 neutral proteinases. Half-degraining decreased the activities of proteinases while not affected the

5 activities of a-amylase and $\beta$-amylase. Nevertheless, these results indicate that the earlier

6 senescence of defoliated plants might be due to the increases in these hydrolytic enzymes, while

7 the delayed leaf senescence of half-degrained plants might be caused by the decreased starch

8 degradation.

9 Vegetative organ CTKs play an important role in regulating senescence which was associated with a delay of proteolytic activity and thus the $\mathrm{N}$ remobilization to developing grains (Noodén et al., 1997; Roberts et al., 2011; Gregersen et al., 2013). Therefore, we speculate that the decrease in the CTK content may be associated with the increases in proteolytic activity in flag leaf of defoliated plants.

In conclusion, reduced sink/source ratio due to half-degraining delayed wheat leaf senescence while higher sink/source ratio due to defoliation caused higher amount of ROS production and facilitated the degradation of chlorophyll proteins, carbohydrate and thus the plant senescence.

CTKs, IAA, $\mathrm{GA}_{3}$, JA and $\mathrm{SA}$ and interactions among these hormones had major roles in regulating source capability and sink strength and thereby impacting the process of leaf senescence. Sink and source manipulations induces a lot of deferentially expressed proteins, which were mainly involved in ROS scavenging, leaf photosynthesis, carbon and nitrogen metabolism, 
1 carbon and nitrogen was promoted in flag leaf of the defoliated plants but retarded in the

2 half-degrained plants, which in turn impacted the carbon and nitrogen metabolisms in the grain.

3 Although trimming the spikes did not produce significant changes in duration of grain filling, the

$4 \quad$ single grain growth was enhanced by half-spike removal and depressed by defoliation, indicating

5 that the yield potential of wheat is limited by both sink capacity and source availability. Our

6 results indicate that future yield improvements may be achieved by strengthening both the source

7 and sink capacity in breeding for increased yield potential in wheat.

\section{$8 \quad$ Material and Methods}

\section{$9 \quad$ Site, experiment and design}

The experiments were conducted in $2017-2018$ in a field at an experimental station $\left(36^{\circ} 42^{\prime} \mathrm{N}\right.$, $117^{\circ} 4^{\prime} \mathrm{E}$; altitude $48 \mathrm{~m}$ ) of the Shandong Academy of Agricultural Sciences, China. The soil was a fine loamy. Wheat cultivars Jimai 23 was sown at a seeding rate of $10 \mathrm{~g} \mathrm{~m}^{-2}$ on October 8 . Plots were fertilized before planting with $10 \mathrm{~g} \mathrm{~m}^{-2} \mathrm{P}_{2} \mathrm{O}_{5}, 10 \mathrm{~g} \mathrm{~K}_{2} \mathrm{O} \mathrm{m}^{-2}$ and $7.5 \mathrm{~g} \mathrm{~N} \mathrm{~m}^{-2}$. At the shooting stage (Zadoks stage 31), $15 \mathrm{~g} \mathrm{~N} \mathrm{~m}^{-2}$ was top-dressed with urea.

\section{Source and Sink Manipulations}

To analyze the effects of sink and source reduction on grain growth, sink-source manipulations were conducted as follow: (1) half of the spikelets were removed from one side of the spikes by hand to double the assimilate availability for the remaining grains; (2) all leaves of culms except flag leaf were removed to reduce the source assimilate availability. Each manipulation was performed in three 1-m sections of the rows at 2 days after anthesis. Three 1-m sections were selected and were left intact as a control.

Measurement of Photochemical Reflectance Index (PRI), Normalized Difference 


\section{Vegetation Index (NDVI) and the Soil-plant Analyses Development (SPDA) Values of}

\section{$2 \quad$ Flag Leaves}

3 Leaf NDVI and PRI values were measured with a PlantPen instrument (Photon Systems

4 Instruments, Brno, Czech Republic) on 30 leaves per plot. The SPAD index were determined on

5 the at least 30 flag leaves per plot using a chlorophyll meter (SPAD-502 plus, Konica Minolta,

6 INC. Japan) at 8, 16 and 24 days after manipulation (DAM). Data from each plot were averaged to

7 obtain a mean.

8 Chlorophyll Fluorescence Assay and Imaging

9 Chlorophyll fluorescence analysis was performed at different stages to determine the maximum

PSII quantum yield $(F v / F m)$ and the effective PSII quantum yield $\left(\Phi_{\text {PSII }}\right)$ in the flag leaves using a as described by Kong et al. (2000).

\section{Transmission Electron Microscopy}

Five flag leaves were randomly collected from three plots of each treatment and the middle part of the leaf blade was sectioned into $2 \mathrm{~m} \times 2 \mathrm{~m}$ patches using a razor blade. The collected samples were immediately fixed in $2.5 \%$ glutaraldehyde solution in $100 \mathrm{mM}$ phosphate buffer (PB, pH 7.2) and stored for $14 \mathrm{~h}$ at $4^{\circ} \mathrm{C}$. After washing with the buffer, the samples were post-fixed with $1 \%$ $(\mathrm{w} / \mathrm{v}) \mathrm{OsO} 4$ in the same buffer at $4^{\circ} \mathrm{C}$ for $4 \mathrm{~h}$. The samples were then dehydrated in an ethanol series, transferred into propylene oxide and finally embedded in polymerized Epon812 resin. 
1 microscopy (JEM-1200EX; JEOL Ltd., Tokyo, Japan) at $80 \mathrm{kV}$.

\section{Hormone Analysis}

3 Flag leaves or spikes in triplicate of each treatment were collected at 8, 16 and 24 DAM,

4 immediately frozen in liquid nitrogen and then stored at $-80^{\circ} \mathrm{C}$ and then the leaves and grains were

5 used for each hormone analysis. The hormone was extracted using extraction kit and the contents

6 of phytohormones were measured following the instructions of manufacturer (SuZhou Comin

7 Biotechnology; Suzhou, China).

8 Briefly, for the extraction and purification of zeatin, zeatin ribuside, kinetin, $\mathrm{GA}_{3}$ and IAA,

9 sample (approximately $0.10 \mathrm{~g}$ flag leaves or grains) was ground in a mortar (on ice), and $5 \mathrm{ml} 80 \%$ $(\mathrm{v} / \mathrm{v})$ methanol extraction solution containing $1 \mathrm{mM}$ butylated hydroxytoluene was used as an antioxidant. The methanolic extracts were incubated at $4^{\circ} \mathrm{C}$ over night and centrifuged at $10,000 \mathrm{~g}$ for 15 min at $4^{\circ} \mathrm{C}$. The supernatants were dried with $\mathrm{N}_{2}$ at $40^{\circ} \mathrm{C}$, dissolved in $200 \mu \mathrm{L}$ methanol and filtered through a 0.45- $\mu \mathrm{m}$ membrane. High Performance Liquid Chromatography (HPLC; Rigol L3000, Beijing, China) with Kromasil C18 reverse phase column was used to measure the hormone content. The mobile phase was prepared by mixing methanol and ultrapure water at a ratio of $2: 3(\mathrm{v} / \mathrm{v})$. Injection volume was $10 \mu \mathrm{L}$, flow rate $0.8 \mathrm{ml} / \mathrm{min}$, column temperature $35^{\circ} \mathrm{C}$, aliasing time $60 \mathrm{~min}$, and detection wavelength $254 \mathrm{~nm}$. Three independent biological replicates of each sample were performed.

For SA and JA analysis, sample (approximately $0.10 \mathrm{~g}$ ) was grounded to fine powder in liquid nitrogen and extracted with $1.0 \mathrm{ml}$ of $90 \%$ methanol over night at $4^{\circ} \mathrm{C}$. After centrifugation at $8,000 \times \mathrm{g}$ for $10 \mathrm{~min}$, the precipitate was re-extracted with $0.5 \mathrm{ml}$ of $90 \%$ methanol for $2 \mathrm{~h}$ and re-centrifuged. The supernatants from both extractions were combined and air-dried in a water 
1 bath at $40^{\circ} \mathrm{C}$. The dried samples were resuspended in solvent containing $20 \mu \mathrm{L}$ of $1 \mathrm{mg} / \mathrm{ml}$

2 trichloroacetic acid and $1 \mathrm{ml}$ of ethylacetate/cyclopentane $(1: 1, \mathrm{v}: \mathrm{v})$ by vigorous vortexing for 30

3 min and centrifuged at $8,000 \times \mathrm{g}$ for $10 \mathrm{~min}$. The top organic phase (including SA and JA) was

4 dried, dissolved in mobile phase and injected into a reverse phase C18 HPLC column equipped

5 with a fluorescence detector for the analysis of SA measured. For SA, the mobile phase was

6 prepared by mixing methanol and ultrapure water at a ratio of 2:3 (v/v). Injection volume was 10

$7 \mu \mathrm{L}$, flow rate $0.8 \mathrm{ml} / \mathrm{min}$, column temperature $35^{\circ} \mathrm{C}$, aliasing time $45 \mathrm{~min}$ and monitored with

8 excitation at $294 \mathrm{~nm}$ and emission at $426 \mathrm{~nm}$. For JA, the mobile phase was prepared by mixing

9 methanol and $0.1 \%$ formic acid $(65 \%: 35 \%, v / v)$. Injection volume was $10 \mu \mathrm{L}$, flow rate 0.8

$10 \mathrm{ml} / \mathrm{min}$, column temperature $35^{\circ} \mathrm{C}$, aliasing time $30 \mathrm{~min}$ and monitored at $230 \mathrm{~nm}$. At least three

11 independent biological replicates of each sample were performed.

\section{Protein Preparation}

13 Leaves tissue (approximately $0.1 \mathrm{~g} \mathrm{FW}$ for each biological replicate) was ground into a fine

powder in liquid nitrogen and thoroughly transferred to an Eppendorf tube. To the tube, $1 \mathrm{ml}$ of

15

pre-cooled phenol extraction buffer was added, incubated the mixture at room temperature for 10 min and then added $1 \mathrm{ml}$ phenol saturated with Tris- $\mathrm{HCl}(\mathrm{pH} 8.0)$. The mixture was shaken for 40 min at $4^{\circ} \mathrm{C}$. After centrifugation at $12,000 \mathrm{~g}$ for $15 \mathrm{~min}$ at $4^{\circ} \mathrm{C}$, the upper phenolic phase was then collected, the debris was removed and the protein was precipitated with pre-cooled $100 \mathrm{mM}$ ammonium acetate-methanol solution for $12 \mathrm{~h}$ at $-20^{\circ} \mathrm{C}$. After centrifugation, the pellet was washed three times with cold acetone and air-dried for $5 \mathrm{~min}$. The protein was resuspended in 600 $\mu \mathrm{L}$ SDT (4\% SDS, $100 \mathrm{mM}$ Tris-HCl, $1 \mathrm{mM}$ DTT, pH7.6), boiled water bath for 5 min and centrifuged at $12,000 \mathrm{~g}$ for $10 \mathrm{~min}$ at room temperature. The sample was collected and stored at 
$1-80^{\circ} \mathrm{C}$ for iTRAQ analysis. The protein concentration was determined according to Bradford assay

2 (Bradford, 1976).

\section{Trypsin Digestion and iTRAQ Labeling}

4 Approximately $100 \mu \mathrm{g}$ protein of each biological replicate was used for digestion. Firstly, the

5 protein sample was reduced by the addition of $120 \mu \mathrm{L}$ buffer $(10 \mathrm{mM}$ DTT, $8 \mathrm{M}$ Urea, $100 \mathrm{mM}$

$6 \mathrm{TEAB}, \mathrm{pH} 8.0$ ) at $60^{\circ} \mathrm{C}$ for $1 \mathrm{~h}$, and then alkylated using $50 \mathrm{mM}$ iodoacetamide for $40 \mathrm{~min}$ at room

7 temperature in the dark. Subsequently, the protein sample was diluted with $100 \mu \mathrm{L} 100 \mathrm{mM}$ TEAB.

8 Then, $2 \mu \mathrm{L}$ sequencing-grade trypsin $\left(1 \mu \mathrm{g} / \mu \mathrm{L}\right.$; Promega) was added for the digestion at $37^{\circ} \mathrm{C}$ for

$9 \quad 12 \mathrm{~h}$. After centrifugation at 12,000 g for $20 \mathrm{~min}$, the supernatant was collected and lyophilized.

Briefly, one unit of the iTRAQ reagent (defined as the amount of reagent required to label $100 \mu \mathrm{g}$

11 of protein). The sample was thawed and reconstituted in $100 \mu \mathrm{L} 100 \mathrm{mM}$ TEAB. The $100 \mu \mathrm{L}$

iTRAQ reagent was transferred to the sample tube and labeled differently by incubation for $2 \mathrm{~h}$ at room temperature. After addition of $200 \mu \mathrm{L}$ water to quench the labeling reaction, the solution was

\section{4 lyophilized.}

\section{Mass Spectrometry Analysis}

The labeled peptides were subjected to nanospray Flex source and analyzed by Q-Exactive mass spectrometer (Thermo, USA). Samples were loaded by a capillary C18 trap column $(2 \mathrm{~cm} \times 75 \mu \mathrm{m})$ and then separated by a C18 column $(15 \mathrm{~cm} \times 75 \mu \mathrm{m})$ on an EASY-nLC ${ }^{\mathrm{TM}} 1200$ system (Thermo, USA). The flow rate was $300 \mathrm{~nL} / \mathrm{min}$ and linear gradient was $90 \mathrm{~min}$ (from 5 - 85\% B over $67 \mathrm{~min}$; mobile phase $\mathrm{A}=2 \% \mathrm{ACN} / 0.1 \% \mathrm{FA}$ and $\mathrm{B}=95 \% \mathrm{ACN} / 0.1 \% \mathrm{FA})$. Full MS scans were acquired in the mass range of $300-1800 \mathrm{~m} / \mathrm{z}$ with a mass resolution of 70000 and the automatic gain control (AGC) target value was set at 1000000 . The twelve most intense peaks in MS were fragmented 
1 with higher-energy collisional dissociation (HCD) with a normalized collision energy of $28 \%$.

2 MS/MS spectra were obtained with the tandem mass spectrum resolution of 35000, an AGC target of

350000 and a max injection time of $100 \mathrm{~ms}$. The Q-E dynamic exclusion was set for $30.0 \mathrm{~s}$ and run

$4 \quad$ under positive mode.

\section{$5 \quad$ Protein Identification and Quantification}

6 The resulting MS/MS Spectral data files were analyzed using Proteome Discoverer ${ }^{\mathrm{TM}} 1.3$ (Thermo,

7 USA) software using the SEQUEST® search engine and searched against a Uniprot

8 Triticumaestivu. fasta database for wheat at $1 \%$ false discovery rate (FDR). Mass error of

9 precursor ions and fragment ions was set to $10 \mathrm{ppm}$ and $0.02 \mathrm{Da}$, respectively.

The screening criteria of reliable proteins were as follows: unique peptide $\geq 1$, removal of

invalid values and antilibrary data, and screening of differentially expressed protein based on the reliable proteins. To screen differential proteins a Student's $t$-test $P<0.05$ and fold change $>1.3$ or $<0.77$ across the flag leaf samples or more than 1.5 -fold or less than 0.67 -fold were selected across the grain samples from a control and two treatments were applied based two experiments.

Bioinformatics Analysis 
1 was high, as indicated by solid lines or dashed lines.

\section{Enzyme Assays}

3 For total amylase activity, flag leaf (approximately $0.1 \mathrm{~g} \mathrm{FW}$ ) was homogenized in a pre-chilled

4 mortar and pestle with $1 \mathrm{ml}$ cooled distilled water. After adding another $9 \mathrm{ml}$ of distilled water, the

5 mixture was placed at room temperature for $20 \mathrm{~min}$ to extract total amylase. Then the homogenate

6 was centrifuged at $12,000 \mathrm{rpm}$ for $15 \mathrm{~min}$ at $4^{\circ} \mathrm{C}$. The supernatant was separated and used as the

7 enzyme extract. To $1 \mathrm{ml}$ enzyme extract, $1 \mathrm{ml}$ soluble starch $(1 \%, \mathrm{w} / \mathrm{v})$ or $1 \mathrm{ml}$ distilled water (control)

8 was added and incubated at $40^{\circ} \mathrm{C}$ for $5 \mathrm{~min}$. Subsequently, $2 \mathrm{ml}$ of 3, 5-dinitrosalicylic acid reagent $(1 \%$

9 (w/v) 3,5-dinitrosalicylic acid and $100 \mathrm{mM}$ phosphate buffer (pH 7.0)) was added to the mixture

before heating in a boiling water bath. Absorbance was measured at $540 \mathrm{~nm}$ using a

11 spectrophotometer. To measure $\alpha$-amylase (EC 3.2.1.1) activity, $\beta$-amylase (EC 3.2.1.2) in the crude

enzyme extract was inactivated by heating at $70^{\circ} \mathrm{C}$ for $15 \mathrm{~min}$. All of the other steps were the same as

the assay of total amylase activity described above. The activity of $\beta$-amylase was calculated as the

difference between total amylase and $\alpha$-amylase activity. The enzyme activity was expresses as the

amount of enzyme catalyzing to the production of $1 \mathrm{mg}$ reducing sugar per min per mg protein.

Protease (EC 3.4.21.40) activity was determined spectrophotometrically using casein as the 
1 absorbance was then colorimetrically measured at $680 \mathrm{~nm}$. The $\mathrm{pH}$ levels of acid proteinase,

2 neutral proteinase, and alkaline proteinase buffer solutions were 3.6, 7.5 and 11, respectively. The

3 activity of proteases was estimated by measuring residues of tyrosine and other aromatic amino

4 acids released from hydrolyzed proteins according to a standard curve. The activity was expressed

5 as nmol tyrosine released per min per mg protein.

6 Grain Mass

7 Eighty plants were harvested from each plot at maturity and threshed by hand. The grains were

8 oven-dried at $60^{\circ} \mathrm{C}$ to a constant weight. Grain mass were then weighed and grain number were

9 counted to obtain single grain mass. Grain mass and grain number were showed based on 10 half-spike.

\section{Acknowledgements}

This work was supported by the Natural Science Foundation of Shandong Province (ZR2016CM39), the Shandong Project of Leading Talent for Mount Tai Industry (LJNY201601), the Shandong Modern Agricultural Technology and Industry System (SDAIT-01-06) and the National Earmarked Fund for Modern Agro-industry Technology Research System (CARS-3-1-21). We Thank Shanghai Luming Biotechnology CO., LTD for proteomics services and bioinformatic support.

\section{References}

Abhinandan K, Skori L, Stanic M, Hickerson NMN, Jamshed M, Samuel MA. 2018. Abiotic stress signaling in wheat - an inclusive overview of hormonal interactions during abiotic stress 
1

2

3

4

5

6

7

8

9

responses in wheat. Front Plant Sci 9, 734

Afzal I, Basra SMA, Iqbal A. 2005. The effects of seed soaking with plant growth regulators on seedling vigor of wheat under salinity stress. J Stress Physiol Biochem 1, 6-14

Beed FD, Paveley ND, Sylvester-Bradley R. 2007. Predictability of wheat growth and yield in light-limited conditions. J Agr Sci 145, 63-79

Beers RF Jr, Sizer IW. 1952. A spectrophotometric method for measuring the breakdown of hydrogen peroxide by catalase. J Biol Chem 195, 133-140

Biswas AK, Mondal SK. 1986. Regulation by kinetin and abscisic acid of correlative senescence in relation to grain maturation, source-sink relationship and yield of rice (Oryza sativa L.). Plant Growth Regul 4(3), 239-245

Borrás L, Slafer GA, Otegui ME. 2004. Seed dry weight response to source-sink manipulations in wheat, maize and soybean: a quantitative reappraisal. Field Crops Res 86, 131-146

Buchanan-Wollaston V, Earl S, Harrison E, Mathas E, Navabpour S, Page T, Pink D. 2003. The molecular analysis of leaf senescence - a genomics approach. Plant Biotech J 1, 3-22

Calderini DF, Reynolds MP. 2000. Changes in grain weight as a consequence of de-graining treatments at pre- and post-anthesis in synthetic hexaploid lines of wheat (Triticum durum $\times T$. tauschii). Aus J Plant Physiol 27, 183-191

Calderini DF, Reynolds MP, Slafer GA. 2006. Source-sink effects on grain weight of bread wheat, durum wheat, and triticale at different locations. Aust J Agr Res 57, 227-233

Carrión CA, Costa ML, Martínez DE, Mohr C, Humbeck K, Guiamet JJ. 2013. In vivo inhibition of cysteine proteases provides evidence for the involvement of 'senescence-associated vacuoles' in chloroplast protein degradation during dark-induced 
1

3

4

5

6

7

8

senescence of tobacco leaves. J Exp Bot 64, 4967-4980

Cartelle J, Pedró A, Savin R, Slafer GA. 2006. Grain weight responses to post-anthesis spikelet-trimming in an old and a modern wheat under Mediterranean conditions. Europ $\mathrm{J}$ Agron 25, 365-371

Chang TG, Zhu XG. 2017. Source-sink interaction: a century old concept under the light of modern molecular systems biology. J Exp Bot 68, 4417-4431

Chen M, Maodzeka A, Zhou L, Ali E, Wang Z, Jiang L. 2014. Removal of DELLA repression promotes leaf senescence in Arabidopsis. Plant Sci 219-220, 26-34

Deng L, Qin P Liu Z, Wang G, Chen W, Tong J, Xiao L, Tu B, Sun Y, Yan W, He H, Tan J, Chen X, Wang Y, Li S, Ma B. 2017. Characterization and fine-mapping of a novel premature leaf senescence mutant yellow leaf and dwarf 1 in rice, Plant Physiol Bioch 111,50-58

Desclos M, Etienne P, Coquet L, Jouenne T, Bonnefoy J, Segura R, Reze S, Ourry A, Avice JC. 2009. A combined ${ }^{15} \mathrm{~N}$ tracing/proteomics study in Brassica napus reveals the chronology of proteomics events associated with $\mathrm{N}$ remobilisation during leaf senescence induced by nitrate limitation or starvation. Proteomics 9, 3580-3608

Dietrich JT, Kaminek M, Blevins DG, Reinbott TM, Morris RO. 1995. Changes in cytokinins and cytokinin oxidase activity in developing maize kernels and the effects of exogenous cytokinin on kernel development. Plant Physiol Biochem 33, 327-336

Drake R, John I, Farrell A, Cooper W, Schuch W, Grierson D. 1996. Isolation and analysis of cDNAs encoding tomato cysteine proteases expressed during leaf senescence. Plant Mol Biol $30,755-767$

Du Y, Fan L, Tian C, Wu T. 2018. Auxin positively regulates nitrogen remobilization in 
1

2

3

4

5

6

7

8

9

cucumber leaves. Hortic Environ Biotechnol 59, 189

Exposito-Rodriguez M, Laissue PP, Yvon-Durocher G, Smirnoff N, Mullineaux PM. 2017.

Photosynthesis-dependent $\mathrm{H}_{2} \mathrm{O}_{2}$ transfer from chloroplasts to nuclei provides a high-light signalling mechanism. Nat Commun 8,4

Fazli IS, Abdin MZ, Jamal A, Ahmad S. 2005. Interactive effect of sulphur and nitrogen on lipid accumulation, acetyl-CoA concentration and acetyl-CoA carboxylase activity in developing seeds of oilseed crops (Brassica compestris L. and Eruca sativa Mill.). Plant Sci 168, 29-36

Ford KL, Cassin A, Bacic A. 2011. Quantitative proteomic analysis of wheat cultivars with differing drought stress tolerance. Front Plant Sci 2,44.

Fu J, Huang ZH, Wang ZQ, Yang JC, Zhang JH. 2011. Pre-anthesisnon-structural carbohydrate reserve in the stem enhances the sink strength of inferior spikelets during grain filling of rice. Field Crops Res 123, 170-182

Foulkes MJ, Slafer GA, Davies WJ, Berry PM, Sylvester-Bradley R, Martre P, Calderini DF, Griffiths S, Reynolds MP. 2011. Raising yield potential of wheat. III. Optimizing partitioning to grain while maintaining lodging resistance. J Exp Bot 62, 469-486

Gallogly MM, Mieyal JJ. 2007. Mechanisms of reversible protein glutathionylation in redox signaling and oxidative stress. Curr Opin Pharmacol 7, 381-391

Geigenberger P, Thormählen I, Daloso DM, Fernie AR. 2017. The unprecedented versatility of the plant thioredoxin system. Trends Plant Sci 22, 249-262

Golestan Hashemi FS, Ismail MR, Rafii MY, Aslani F, Miah G, Muharam FM. 2018. Critical multifunctional role of the betaine aldehyde dehydrogenase gene in plants, Biotech Biotech Eq doi: $10.1080 / 13102818.2018 .1478748$ 
1 Gregersen P L, Culetic A, Boschian L, Krupinska K. 2013. Plant senescence and crop

2 productivity. Plant Mol Biol 82, 603-622

3 Gulyaeva NV, Obidin AB, Marinov BS. 1987. Modulation of superoxide dismutase by electron

4 donors and acceptors. FEBS lett 211,211-214.

5 Hayano T, Hirose M, Kikuchi M. 1995. Protein disulfide isomerase mutant lacking its isomerase

$6 \quad$ activity accelerates folding in the cell. FEBS Lett 377,505-511

7 He P, Osaki M, Takebe M, Shinano T, Wasaki J. 2005. Endogenous hormones and expression

of senescence-related genes in different senescent types of maize. J Exp Bot 56,1117-1128

9

Hicks LM, Cahoon RE, Bonner ER, Rivard RS, Sheffield J, Jez JM. 2007. Thiol-based regulation of redox-active glutamate-cysteine ligase from Arabidopsis thaliana. Plant Cell $19,2653-2661$

Hui Z, Tian FX, Wang G, Wang GP, Wang W. 2012. The antioxidative defense system is involved in the delayed senescence in a wheat mutant tasg1. Plant Cell Rep 31,1073-1084

Hollmann J, Gregersen PL, Krupinska K. 2014. Identification of predominant genes involved in regulation and execution of senescence-associated nitrogen remobilization in fag leaves of feld grown barley. J Exp Bot 65, 3963-3973

Jan S, Abbas N, Ashraf M, Ahmad P. 2019. Roles of potential plant hormones and transcription factors in controlling leaf senescence and drought tolerance. Protoplasma 256, 313-329

Jessica B, Pierre M, Bruno A. 2008. Dynamics of light and nitrogen distribution during grain filling within wheat canopy. Plant Physiol 148, 1707-1720

Kang G, Peng X, Wang L, Yang Y, Shao R, Xie Y, Ma D, Wang C, Guo T, Zhu Y. 2015. Ultrastructural observation of mesophyll cells and temporal expression profiles of the genes 
1 involved in transitory starch metabolism in flag leaves of wheat after anthesis. Physiol

$2 \quad$ Plantarum 153,12-29

3 Kanwischer M, Porfirova S, Bergmüller E, and Dörmann P. 2005. Alterations in tocopherol

4 cyclase activity in transgenic and mutant plants of Arabidopsis affect tocopherol content,

$5 \quad$ tocopherol composition, and oxidative stress. Plant Physiol 137,713-723

6 Karp NA, Huber W, Sadowski PG, Charles PD, Hseter SV, Lilley KS. 2010. Addressing

7 accuracy and precision issues in iTRAQ quantitation. Mol Cell Proteomics 9,1885-1897

8 Kayum MA, Park JI, Nath UK, Saha G, M Kumar Biswas, Kim HT, Ill-Sup Nou. 2017.

9

Genome-wide characterization and expression profiling of PDI family gene reveals function as abiotic and biotic stress tolerance in Chinese cabbage (Brassica rapa ssp. pekinensis). BMC Genomics 18,885

Kong L, Guo H, Sun M. 2015. Signal transduction during wheat grain development. Planta 241, $789-801$

Kong L, Wang F, Feng B, Li S, Si J, Zhang B. 2010. The structural and photosynthetic characteristics of the exposed peduncle of wheat (Triticum aestivum L.): an important photosynthate source for grain-filling. BMC Plant Biol 10, 141

Kong LA, Xie Y, Hu L, Si J, Wang Z. 2017. Excessive nitrogen application dampens antioxidant capacity and grain filling in wheat as revealed by metabolic and physiological analyses. Scientific Reports 7,43363

Kong LA, Xie Y, Sun MZ, Si JS, Hu L. 2016. Comparison of the photosynthetic characteristics in the pericarp and flag leaves during wheat (Triticum aestivum L.) caryopsis development. Photosynthetica 54 (1), 40-46 
1 Kruk B, Calderini DF, Slafer GA. 1997. Source-sink ratios in modern and old wheat cultivars. J

$2 \quad$ Agric Sci 128, 273-281

3 Liang D, Gao F, Ni Z, Lin L, Deng Q, Tang Y, Wang X, Luo X, Xia H. 2018. Melatonin

4 Improves Heat Tolerance in Kiwifruit Seedlings through Promoting Antioxidant Enzymatic

$5 \quad$ Activity and Glutathione S-Transferase Transcription. Molecules 23, 584

6 Li Z, Wang F, Lin W, Zhao Q, Liu J, Cheng F. 2017. Carbon reserve and remobilization in leaf

7 sheaths during the grain-filling stage in response to leaf early senescence. Acta Physiol Plant

$8 \quad 39,10$

9 LiH, Wang G, Liu S, An Q, Zheng Q, Li B, Li Z. 2014. Comparative changes in the antioxidant system in the flag leaf of early and normally senescing near-isogenic lines of wheat (Triticum aestivum L.). Plant Cell Rep 33, 1109-1120

Li W, Zhang H, Li X, Zhang F, Liu C, Du Y, Gao X, Zhang Z, Zhang X, Hou Z, Zhou H, Sheng X, Wang G, Guo Y. 2017. Intergrative metabolomic and transcriptomic analyses unveil nutrient remobilization events in leaf senescence of tobacco. Sci Rep 7,12126

Liu W, Harrison DK, Chalupska D, Gornicki P, O'Donnell CC, Adkins SW, Haselkorn R, Williams RR. 2007. Single-site mutations in the carboxyltransferase domain of plastid acetyl-CoA carboxylase confer resistance to grass-specific herbicides. P Natl Acad Sci 104, $3627-3632$.

Liu X, Gai Z, Tao F, Tang H, Xu P. 2012. Carotenoids play a positive role in the degradation of heterocycles by Sphingobium yanoikuyae. PLoS ONE 7(6),e39522

Liu Y, Liang H, Lv X, Liu D, Wen X, Liao Y. 2016. Effect of polyamines on the grain filling of wheat under drought stress. Plant Physiol Bioch 100, 113-129. 
1 Liu J, Wu YH, Yang JJ, Liu YD, Shen FF. 2008. Protein degradation and nitrogen remobilization

2 during leaf senescence. J Plant Biol 51, 11-19

3 Lur HS, Setter TL. 1993. Endosperm development of maize defective kernel (dek) mutants.

$4 \quad$ Auxin and cytokinin levels. Ann Bot (London) 72,1-6

5 Lv X, Han J, Liao Y, Liu Y. 2017. Effect of phosphorus and potassium foliage application

6 post-anthesis on grain filling and hormonal changes of wheat. Field Crops Res 214, 83-93

7 Lv Y, Zhang S, Wang J, Hu Y. 2016. Quantitative proteomic analysis of wheat seeds during artificial ageing and priming using the isobaric tandem mass tag labeling. PLoS ONE 11(9),

9 $\mathrm{e} 0162851$

Lyu JI, Baek SH, Jung S, Chu H, Nam HG, Kim J, Lim PO. 2017. High-throughput and computational study of leaf senescence through a phenomic approach. Front Plant Sci 8,250

Ma YZ, MacKown CT, van Sanford DA. 1996. Differential effects of partial spikelet removal and defoliation on kernel growth and assimilate partitioning among wheat cultivars. Field Crops Res 47, 201-209

Maloney VJ, Park JY, Unda F, Mansfield SD. 2015. Sucrose phosphate synthase and sucrose phosphate phosphatase interact in planta and promote plant growth and biomass accumulation. J Exp Bot 66, 4383-4394

Moschen S. Luoni S, Rienzo JAD, et al.. 2016. Integrating transcriptomic and metabolomic analysis to understand natural leaf senescence in sunfower. Plant Biotech J 14, 719-734

Noodén LD, Guiamét JJ, John I. 1997. Senescence mechanisms. Physiol Plant 101,746-753

Parihar P, Singh S, Singh R, Singh VP, Prasad SM. 2015. Effect of salinity stress on plants and its tolerance strategies: a review. Environ Sci Pollut R 22, 4056-4075 
1 Paul MJ, Foyer CH. 2001. Sink regulation of photosynthesis. J Exp Bot 52, 1383-1400

2 Reguera M, Peleg Z, Abdel-Tawab YM, Tumimbang EB, Delatorre CA, Blumwald E. 2013.

3 Stress-induced cytokinin synthesis increases drought tolerance through the coordinated

4 regulation of carbon and nitrogen assimilation in rice. Plant Physiol 163,1609-1622

5 Rijavec T, Kovać M, Kladnik A, Chourey PS Dermastia M. 2009. Comparative study on the role

6 of cytokinins in caryopsis development in the maize miniature 1 seed mutant and its wild type.

$7 \quad$ J Integr Plant Biol 51, 840-849

8 Roberts IN, Caputo C, Kade M, Criado MV, Barneix AJ. 2011. Subtilisin-like serine proteases involved in N remobilization during grain filling in wheat. Acta Physiol Plant 33,1997-2001

Serrago RA, Alzueta I, Savin R, Slafer GA. 2013. Understanding grain yield responses to source-sink ratios during grain filling in wheat and bar ley under contrasting environments. Field Crops Res 150, 42-51

Shannon P, Markiel A, Ozier O, Baliga N S, Wang JT, Ramage D, Amin N, Schwikowski B, Ideker T. 2003. Cytoscape: A software environment for integrated models of biomolecular interaction networks. Genome Res 13,2498-2504

Seth AK, Waering PE. 1967. Hormone-directed transport of metabolites and its possible role in plant senescence. J Exp Bot 18, 65-77

Singh V, Sharma V, Katara P. 2016. Comparative transcriptomics of rice and exploitation of target genes for blast infection. Agri Gene 1, 143-150

Singh G, Gerung SB. 1982. Hormonal role in the problem of sterility in Oryza sativa. Plant Physiol Biochem 9, 22-23

Slafer GA, Savin R. 1994. Source-sink relationships and grain mass at different positions within 
1 the spike in wheat. Field Crops Res 37, 39-49

2 Smith AM, Zeeman SC, Smith SM. 2005. Starch degradation. Annu Rev Plant Biol 56,73-98

3 Street J, Jordan J, Ebelhar M, Boykin D. 1986. Plant height and yield responses of rice to

4 paclobutrazol. Agron J 78(2),288-291

Suzuki N, Koussevitzky S, Mittler R, Miller G. 2012. ROS and redox signalling in the response of plants to abiotic stress. Plant Cell Environ 35,259-270

Tamaki H, Reguera M, Abdel-Tawab YM, Takebayashi Y, Kasahara H, Blumwald E. 2015. Targeting hormone-related pathways to improve grain yield in rice: a chemical approach. PLoS ONE 10(6), e0131213

Thomas H, Ougham H. 2014. The stay-green trait. J Exp Bot 65,3889-3900

Vicente R, Vergara-D’́ız O, Medina S, Chairi F, Kefauver SC, Bort J, Serret MD, Aparicio N, Araus JL. 2018. Durum wheat ears perform better than the flag leaves under water stress: gene expression and physiological evidence. Environ Exp Bot 153, 271-285

Wang F, Cheng F, Zhang G. 2006. The relationship between grain filling and hormone content as affected by genotype and source-sink relation. Plant Growth Regul 49,1-8

Wang P, Liu J, Liu B, Da Q, Feng D, Su J, Zhang Y, Wang J, Wang HB. 2014. Ferredoxin:thioredoxin reductase is required for proper chloroplast development and is involved in the regulation of plastid gene expression in Arabidopsis thaliana. Mol Plant 7 , $1586-1590$

Wang D, Liu H, Zhai G, Wang L, Shao J, Tao Y. 2016. OspTAC2 encodes a pentatricopeptide repeat protein and regulates rice chloroplast development. J Genet Genom 43, 601-608

Wang Z, Wang Y, Hong X, Hu D, Liu C, Yang J, Li Y, Huang Y, Feng Y, Gong H, Li Y, 
1

2

3

4

5

6

7

8

9

10

11

12

Fang G, Tang H, Li Y. 2015. Functional inactivation of UDP- $N$-acetylglucosamine pyrophosphorylase 1 (UAP1) induces early leaf senescence and defence responses in rice. J Exp Bot 66, 973-987

Wang M, You J. 2012. Mass spectrometry for protein quantification in biomarker discovery. Methods Mol Biol 815,199-225

Xu GW, Zhang JH, Lam HM, Wang ZQ, Yang JC. 2007. Hormonal changes are related to the poor grain filling in the inferior spikelets of rice cultivated under non-flooded and mulched condition. Field Crop Res 101, 53-61

Yang JC, Cao YY, Zhang H, Liu LJ, Zhang JH. 2008. Involvement of polyamines in the post-anthesis development of inferior and superior spikelets in rice. Planta 228,137-149

Yang D Li Y, Shi Y, Cui Z, Luo Y, Zheng M, Chen J, Li Y, Yin Y, Wang Z. 2016. Exogenous cytokinins increase grain yield of winter wheat cultivars by improving stay-green characteristics under heat stress. PLoS ONE 11(5), e0155437

Yang JC, Peng SB, Visperas RM, Sanico AL, Zhu QS, Gu SL. 2000. Grain filling pattern and cytokinin content in the grains and roots of rice plants. Plant Growth Regul 30, 261-270

Yang WY, Yong TW, Zhang H. 2002. Studies on improving seedling vigour by soaking hybrid rice seed with uniconazole. S-W China J Agric Sci 15(4),50-54

Yang JC, Zhang JH. 2006. Grain filling of cereals under soil drying. New Phytol 169, 223-236

Yang J, Zhang J. 2010. Grain-filling problem in 'super’ rice. J Exp Bot 61, 1-5

Yang JC, Zhang JH, Wang ZQ, Zhu QS, Wang W. 2001. Hormonal changes in the grains of rice subjected to water stress during grain filling. Plant Physiol 127(1), 315-323

Yang J, Zhang J, Wang Z, Zhu Q, Wei W. 2001c. Remobilization of carbon reserves in response 
2 Yang JC, Zhang JH, Huang ZL, Wang ZQ, Zhu QS, Liu LJ. 2002. Correlation of cytokinin

3

4 levels in the endosperms and roots with cell number and cell division activity during endosperm development in rice. Ann Bot Lond 90, 369-377

Yu SM, Lo SF, Ho THD. 2015. Source-sink communication: regulated by hormone, nutrient, and stress cross-signaling. Trends Plant Sci 20, 844-857.

Zhang W, Cao Z, Zhou Q, Chen J, Xu G, Gu J, Liu L, Wang Z, Yang J, Zhang H. 2016. Grain filling characteristics and their relations with endogenous hormones in large- and small-grain mutants of rice. PLoS ONE 11(10), e0165321

Zhang H, Tan GL, Yang LN, Yang JC, Zhang JH, Zhao BH. 2009a. Hormones in the grains and roots in relation to post-anthesis development of inferior and superior spikelets in japonica/indica hybrid rice. Plant Physiol Biochem 47, 195-204

Zhang H, Turner NC, Poole ML. 2010. Source-sink balance and manipulating sink-source relations of wheat indicate that the yield potential of wheat is sink limited in high-rainfall zones. Crop Pasture Sci 61, 852-861

Zhang ZC, Xue YG, Wang ZQ, Yang JC, Zhang JH. 2009. The relationship of grain filling with abscisic acid and ethylene under non-flooded mulching cultivation. J Agric Sci 147, 423-436

Zhao J, Qiu Z, Ruan B, Kang S, He L, Zhang S, et al. 2015. Functional inactivation of putative photosynthetic electron acceptor ferredoxin $\mathrm{C} 2$ (FdC2) induces delayed heading date and decreased photosynthetic rate in rice. PLoS ONE 10(11), e0143361 


\section{Tables}

2

3 Table 1. Effects of sink-source manipulations on the PRI, NDVI and SPAD values of flag leaf.

\begin{tabular}{|c|c|c|c|c|}
\hline DAT & & PRI & NDVI & SPAD \\
\hline \multirow[t]{3}{*}{8} & Control & $0.030 \mathrm{~b}$ & $7.98 \mathrm{ab}$ & $58.77 \mathrm{ab}$ \\
\hline & Half-degraining & $0.032 \mathrm{a}$ & $8.14 \mathrm{a}$ & $59.83 \mathrm{a}$ \\
\hline & Defoliation & $0.028 b$ & $7.89 \mathrm{ab}$ & $58.07 \mathrm{ab}$ \\
\hline \multirow[t]{3}{*}{16} & Control & $0.026 \mathrm{~cd}$ & $7.47 \mathrm{~cd}$ & $57.27 \mathrm{bc}$ \\
\hline & Half-degraining & $0.028 b c$ & $7.74 \mathrm{bc}$ & $58.03 \mathrm{ab}$ \\
\hline & Defoliation & $0.024 \mathrm{e}$ & $7.26 \mathrm{~d}$ & $56.03 \mathrm{c}$ \\
\hline \multirow[t]{3}{*}{24} & Control & $0.021 \mathrm{f}$ & $6.21 f$ & $38.43 \mathrm{e}$ \\
\hline & Half-degraining & $0.025 \mathrm{de}$ & $6.57 \mathrm{e}$ & $40.73 \mathrm{~d}$ \\
\hline & Defoliation & $0.018 \mathrm{~g}$ & $6.14 f$ & $33.17 \mathrm{f}$ \\
\hline
\end{tabular}


1 Table 2. Effects of sink and source manupulations on the phytohormone contents in wheat flag leaves and grains.

\begin{tabular}{|c|c|c|c|c|c|c|c|c|c|c|c|c|}
\hline Sample & DAM & Treatment & $\begin{array}{l}\text { CTKs } \\
\text { content } \\
(\mu \mathrm{g} / \mathrm{g} \\
\mathrm{FW})\end{array}$ & $\begin{array}{l}\text { Grain/leaf } \\
\text { ratio }\end{array}$ & $\begin{array}{l}\text { IAA } \\
\text { content } \\
(\mu \mathrm{g} / \mathrm{g} \\
\mathrm{FW})\end{array}$ & $\begin{array}{l}\text { Grain/leaf } \\
\text { ratio }\end{array}$ & $\begin{array}{l}\mathrm{GA}_{3} \\
\text { content } \\
(\mu \mathrm{g} / \mathrm{g} \\
\mathrm{FW})\end{array}$ & $\begin{array}{l}\text { Grain/leaf } \\
\text { ratio }\end{array}$ & $\begin{array}{l}\text { Free SA } \\
\text { content } \\
(\mathrm{ng} / \mathrm{g} \mathrm{FW})\end{array}$ & $\begin{array}{l}\text { Grain/leaf } \\
\text { ratio }\end{array}$ & $\begin{array}{l}\mathrm{JA} \\
\text { content } \\
(\mu \mathrm{g} / \mathrm{g} \\
\mathrm{FW})\end{array}$ & $\begin{array}{l}\text { Grain/leaf } \\
\text { ratio }\end{array}$ \\
\hline \multirow[t]{7}{*}{ leaf } & & Half-degraining & $5.86 \mathrm{~b}$ & $\square$ & $2.27 \mathrm{bc}$ & $\square$ & $3.54 \mathrm{~d}$ & $\square$ & $54.23 \mathrm{~cd}$ & $\square$ & $0.56 \mathrm{~d}$ & $\square$ \\
\hline & & Defoliation & $6.02 b$ & $\square$ & $2.11 \mathrm{c}$ & $\square$ & $4.62 \mathrm{c}$ & $\square$ & $49.39 \mathrm{~d}$ & $\square$ & $0.51 \mathrm{de}$ & $\square$ \\
\hline & 16 & Control & $6.67 \mathrm{a}$ & $\square$ & $2.67 \mathrm{ab}$ & $\square$ & $6.07 \mathrm{ab}$ & $\square$ & $56.52 \mathrm{c}$ & $\square$ & $0.81 \mathrm{~b}$ & $\square$ \\
\hline & & Defoliation & $5.80 \mathrm{~b}$ & $\square$ & $1.47 \mathrm{~d}$ & $\square$ & $5.92 \mathrm{ab}$ & $\square$ & $74.07 \mathrm{~b}$ & $\square$ & $0.43 \mathrm{f}$ & $\square$ \\
\hline & 24 & Control & $6.29 \mathrm{ab}$ & $\square$ & $2.74 \mathrm{a}$ & $\square$ & $6.15 \mathrm{a}$ & $\square$ & $88.06 \mathrm{a}$ & $\square$ & 0.47 ef & $\square$ \\
\hline & & Half-degraining & $6.27 \mathrm{ab}$ & $\square$ & $2.06 \mathrm{c}$ & $\square$ & $5.63 b$ & $\square$ & $50.94 d$ & $\square$ & 0.45 ef & $\square$ \\
\hline & & Defoliation & $6.08 \mathrm{~b}$ & $\square$ & $1.33 \mathrm{~d}$ & $\square$ & $6.06 \mathrm{ab}$ & $\square$ & $72.08 \mathrm{~b}$ & $\square$ & $0.35 \mathrm{~g}$ & $\square$ \\
\hline \multirow[t]{6}{*}{ Grain } & 8 & Control & $8.90 \mathrm{~b}$ & $1.33 \mathrm{~cd}$ & $2.78 \mathrm{f}$ & $1.33 \mathrm{e}$ & $1.09 \mathrm{f}$ & $0.24 \mathrm{~d}$ & $34.17 \mathrm{c}$ & $0.85 \mathrm{bc}$ & $0.46 \mathrm{~cd}$ & $0.52 \mathrm{~d}$ \\
\hline & & Half-degraining & $5.91 \mathrm{~d}$ & $1.01 \mathrm{e}$ & $2.99 \mathrm{ef}$ & $1.32 \mathrm{e}$ & $1.42 \mathrm{e}$ & $0.40 \mathrm{ab}$ & $40.77 \mathrm{~b}$ & $0.75 \mathrm{~d}$ & $0.34 \mathrm{f}$ & $0.61 \mathrm{~d}$ \\
\hline & & Defoliation & $11.25 \mathrm{a}$ & $1.94 \mathrm{a}$ & $3.90 \mathrm{~b}$ & $2.66 \mathrm{~b}$ & $2.10 \mathrm{bc}$ & $0.35 b c$ & $35.31 \mathrm{c}$ & $0.48 \mathrm{f}$ & $0.66 \mathrm{a}$ & $1.54 \mathrm{a}$ \\
\hline & 24 & Control & $7.64 \mathrm{c}$ & $1.22 \mathrm{~d}$ & $3.95 b$ & $1.45 \mathrm{de}$ & $2.08 \mathrm{c}$ & $0.34 \mathrm{c}$ & $48.10 \mathrm{a}$ & $0.55 \mathrm{ef}$ & $0.41 \mathrm{e}$ & $0.87 \mathrm{c}$ \\
\hline & & Half-degraining & $6.57 \mathrm{~d}$ & $1.05 \mathrm{e}$ & $3.73 \mathrm{bc}$ & $1.81 \mathrm{c}$ & $2.32 \mathrm{ab}$ & $0.41 \mathrm{a}$ & $47.58 \mathrm{a}$ & $0.93 \mathrm{a}$ & $0.42 \mathrm{de}$ & $0.94 \mathrm{c}$ \\
\hline & & Defoliation & $8.68 \mathrm{~b}$ & $1.43 \mathrm{c}$ & $4.50 \mathrm{a}$ & $3.38 \mathrm{a}$ & $2.44 \mathrm{a}$ & $0.40 \mathrm{ab}$ & $38.49 \mathrm{bc}$ & $0.53 \mathrm{ef}$ & $0.49 \mathrm{c}$ & $1.40 \mathrm{a}$ \\
\hline
\end{tabular}

2 DAM: Days after manipulation 

certified by peer review) is the author/funder. All rights reserved. No reuse allowed without permission.

1 Table 3. Effect of half-degraining and defoliation on the grain number per half-spike, single grain

2 mass and number of spikelets and grain mass per half-spike.

\begin{tabular}{|c|c|c|c|}
\hline & \multicolumn{3}{|l|}{ Grain number } \\
\hline & & Single grain mass (mg) & Grain mass half-spike ${ }^{-1}(\mathrm{mg})$ \\
\hline & \multicolumn{3}{|l|}{ half-spike ${ }^{-1}$} \\
\hline Control & $17.35 \mathrm{~b}$ & $44.27 \mathrm{~b}$ & $768.08 \mathrm{~b}$ \\
\hline Half-degraining & $19.17 \mathrm{a}$ & $48.05 \mathrm{a}$ & $921.12 \mathrm{a}$ \\
\hline Defoliation & $14.51 \mathrm{c}$ & $42.54 \mathrm{~b}$ & $617.26 \mathrm{c}$ \\
\hline
\end{tabular}

3 